\title{
Structure of the human FERRY Rab5 effector complex
}

Dennis Quentin ${ }^{1, *}$, Jan S. Schuhmacher, ${ }^{2, *}$, Björn U. Klink ${ }^{1,3}$, Jeni Lauer ${ }^{2}$, Tanvir R. Shaikh ${ }^{1,4}$, Pim J. Huis in ’t Veld ${ }^{5}$, Luisa M. Welp ${ }^{6}$, Henning Urlaub ${ }^{6,7}$, Marino Zerial ${ }^{2 \dagger}$, Stefan Raunser ${ }^{1 \dagger}$

${ }^{1}$ Department of Structural Biochemistry, Max Planck Institute of Molecular Physiology, 44227 Dortmund, Germany

${ }^{2}$ Max Planck Institute of Molecular Cell Biology and Genetics, 01307 Dresden, Germany

${ }^{3}$ Center for Soft Nanoscience and Institute of Molecular Physics and Biophysics, 48149

Münster, Germany

${ }^{4}$ Institute of Neuropathology, University of Göttingen Medical Center, 37077 Göttingen, Germany

${ }^{5}$ Department of Mechanistic Cell Biology, Max Planck Institute of Molecular Physiology, 44227 Dortmund, Germany

${ }^{6}$ Max Planck Institute for Biophysical Chemistry, 37077 Göttingen, Germany

${ }^{7}$ Institute of Clinical Chemistry, University Medical Center Göttingen, 37075 Göttingen, Germany 
bioRxiv preprint doi: https://doi.org/10.1101/2021.06.21.449265; this version posted June 22,2021 . The copvriaht holder for this preprint (which was not certified by peer review) is the author/funder, who has granted bioRxiv a license to display the preprint in perpetuity. It is made available under aCC-BY-NC-ND 4.0 International license.

*These authors contributed equally

†Correspondence: zerial@mpi-cbg.de, stefan.raunser@mpi-dortmund.mpg.de 


\begin{abstract}
Long-range mRNA transport is crucial for the spatio-temporal regulation of gene expression, and its malfunction is linked to neurological disorders. The pentameric FERRY Rab5 effector complex is the molecular link between mRNA and the early endosome in mRNA intracellular distribution. Here, we determine the cryo-EM structure of the human FERRY complex, composed of Fy-1 to Fy-5. The structure reveals a clamplike architecture, in which two arm-like appendages, each consisting of Fy-2 and a Fy-5 dimer, protrude from the central Fy-4 dimer. We demonstrate that the coiled-coil domains of Fy-2 are flexible and project into opposite directions from the FERRY complex core. While the $C$-terminal coiled-coil acts as binding region for $F y-1 / 3$ and $R$ ab5, both coiled-coils together with Fy-5 bind mRNA. Thus, Fy-2 serves as binding hub that connects not only all five complex subunits, but also mediates the binding to mRNA and to the early endosome via Rab5. The FERRY structure provides novel mechanistic insight into long-distance mRNA transport.
\end{abstract}




\section{Introduction}

Rab small GTPases are master regulators of the endocytic pathway (Pfeffer, 2017; WandingerNess and Zerial, 2014; Zerial and McBride, 2001). They spatially and temporally regulate essential endosomal transport processes including organelle biogenesis, receptor internalization, recycling of membrane-associated molecules and cell-type specific trafficking. Thus, they contribute to the structural and functional integrity of organelles, which is critical for cellular homeostasis in eukaryotes.

Rab GTPases can cycle between an active GTP-bound and an inactive GDP-bound state. This transition is facilitated by guanine exchange factors (GEFs) and GTPase activating proteins (GAPs) (Müller and Goody, 2018). In contrast to inactive cytosolic Rab, activated membrane-associated Rab can recruit a plethora of diverse downstream effector proteins to initiate its membrane remodeling activity (Grosshans et al., 2006; Pfeffer, 2017; WandingerNess and Zerial, 2014; Zerial and McBride, 2001).

Rab5, one of the most extensively studied Rab GTPases, is mainly localized at the early endosome (EE) and regulates endocytosis and EE dynamics (Woodman, 2000). The importance of Rab5 as coordinator of membrane trafficking events is highlighted by deficient internalization of key surface receptors such as the transferrin (Bucci et al., 1992) and the epidermal growth factor receptor (Chen et al., 2009). Moreover, Rab5 controls the internalization of other crucial signaling receptors, including G-protein coupled-receptors, antigen-recognition receptors as well as other receptor tyrosine kinases, all of which are sorted through the EE (Yuan and Song, 2020).

A vast network of interaction partners of Rab5 has been identified, providing Rab5 with one of the most complex interactomes among the Rab family (Christoforidis et al., 1999). This includes GEFs like Rabex-5 and RIN1(Horiuchi et al., 1997; Tall et al., 2001), but also Rab5specific GAPs such as RN-Tre (Lanzetti et al., 2000) and Rab-GAP5 (Haas et al., 2005). Within the large pool of downstream effectors, early endosome antigen 1 (EEA1) is probably the best 
known member, promoting EE membrane tethering and fusion through downstream interaction with SNARE proteins (Murray et al., 2016; Simonsen et al., 1998). Other prominent effectors like Rabaptin-5, Rabankyrin-5, Rabenosyn-5 and APPL1/2 also act downstream and can bind Rab5 via distinct domains such as the FYVE finger (Miaczynska et al., 2004; Nielsen et al., 2000; Schnatwinkel et al., 2004; Stenmark et al., 1996; 1995). Similar to various members of the Ras superfamily, co-structures of Rab effectors bound to their cognate GTPase, including Rab5-Rabaptin-5, Rab4-Rabenosyn-5 and Rab11-FIP2, have provided important insights in the functional interactions between Rab proteins and their effectors and regulators (Eathiraj et al., 2005; Jagoe et al., 2006; Zhu et al., 2004). These studies demonstrate that binding is typically mediated by the switch and inter-switch regions of Rab proteins and either symmetric coiledcoils or $\alpha$-helical bundles of the effector. Moreover, large multiprotein complexes that mediate crucial functions within the endocytic pathway have been shown to be Rab effectors. This includes the two homologous hetero-hexameric tethering complexes, CORVET and HOPS, which interact with Rab5 and Rab7, respectively (Balderhaar and Ungermann, 2013; Kuhlee et al., 2015). Other important complexes such as exocyst and TRAPP, both involved in vesicular transport, are also known to interact with small GTPases (Sacher et al., 2001; Wu et al., 2010), further emphasizing their central role in membrane organization. All these large multiprotein complexes are non-symmetric, highly flexible and dynamic and therefore challenging to analyze structurally. Hence, known structures are often limited to the core of the complexes and it is difficult to reach high resolution (Bröcker et al., 2012; Chou et al., 2016; Kim et al., 2006).

Rab5 is also implicated in long-range endosomal motility (Nielsen et al., 1999). By harnessing the intracellular microtubule (MT) network, EEs can be actively transported via MT motor complexes to distal locations within the cell. These long-distance transport processes are particularly important for cells with sophisticated internal architectures such as neurons, explaining why deficiencies often manifest in compromised cognitive abilities. 
RNA transport serves as a prime example of how spatio-temporal control can influence the expression of genes, underlying essential biological processes such as embryonic development or neuronal plasticity (Medioni et al., 2012; Mofatteh, 2020). Local sites are able to individually regulate gene expression, which is thus not limited to transcriptional control in the nucleus. The sophisticated mRNA localization pattern that is observed in highly polarized cells such as neurons requires active transport of transcripts. Studies in a number of model systems, including yeast and Drosophila melanogaster, were performed in recent years to identify the relevant RNA transport machinery (Vazquez-Pianzola and Suter, 2012). Two distinct active transport pathways have emerged that both utilize the cytoskeletal network in combination with motor proteins: RNA is either transported with the help of accessory proteins, forming ribonucleoprotein particles (RNPs), or associated with endosomal compartments, both actively transported by co-opting cytoskeletal components. The role of the late endosome and lysosome in mRNA localization has been subject of recent research, where Annexin 11A has been proposed to mediate the association between RNA and lysosomes (Liao et al., 2019). While these initial insights are valuable, they are limited to a subclass of the endocytic system. In filamentous fungi, mRNA localization is mediated by the microtubule-based long-distance transport of vesicles, including early endosomes (Zarnack and Feldbrügge, 2010). In neurons, long range transport of various types of cargo, including mRNA, requires active transport, which is mediated by endocytic organelles, particularly the late endosomes (Cioni et al., 2019; De Vos and Hafezparast, 2017). To date, little is known whether and how RNA is transported via early endosomes to its target destination. We have recently identified a novel human 5subunit Rab5 effector complex designated as FERRY (Five-subunit Early endosome RNA and Ribosome intermediarY) complex (Schuhmacher et al., 2021), which interacts with mRNA and thus represents a prime candidate for early endosome-mediated mRNA transport. The FERRY complex is composed of five subunits Tbck (Fy-1), Ppp1r21 (Fy-2), C12orf4 (Fy-3), Cryzl1 
(Fy-4), and Gatd1 (Fy-5), which have a molecular weight of 101, 88, 64, 39 and 23 kDa, respectively (Fig. 1A).

Here, we determined the cryo-EM structure of the FERRY complex at a resolution of $4 \AA$. Together with rotary shadowing EM, hydrogen-deuterium exchange mass spectrometry (HDX-MS) analyses and crosslinking mass spectrometry, the structure demonstrates that FERRY is an elongated complex with a clamp-like architecture at its center and protruding flexible coiled-coil structures at its periphery that mediate the interaction with the EE via Rab5 and mRNA. 


\section{Results}

\section{Architecture of the FERRY Rab5 effector complex}

In order to understand the interaction of the five subunits of FERRY in molecular detail, we overexpressed and purified the subunits as described in Schuhmacher et al. (Schuhmacher et al., 2021) (Methods) and reconstituted the complex in vitro (Fig. S1). We then determined the cryo-EM structure of FERRY to an overall resolution of $4.0 \AA$, applying C2 symmetry (Fig. 1B, Fig. S2-4, Table S1). The structure reveals that the core of FERRY is composed of a dimer of Fy-4, two molecules of Fy-2 and four copies of Fy-5, resulting in a 2:2:4 stoichiometry (Fig. 1B, Fig. S2). The other two subunits, namely Fy-1 and Fy-3, were not resolved in the structure, although SDS-PAGE analysis clearly confirmed their presence in the complex (Fig. S1).

The high quality of the cryo-EM map allowed us to build atomic models for Fy-2 and Fy-4 into the corresponding densities (Fig. 1C, Table S1). Densities corresponding to the four Fy-5 molecules, located at the periphery of the reconstruction, exhibited lower local resolution. To obtain an atomic model for these regions, we initially solved the X-ray structure of Fy-5 at 2.7 Å resolution (Table S2) and subsequently relaxed it into the density (Fig. 1C, Fig. S5, Table $\mathrm{S} 1,2)$.

The structure of the FERRY core reveals an overall clamp-like architecture with two arm-like appendages emanating in opposite directions from a central bulky body (Fig. 1B, C, Fig. S5). Two Fy-4 molecules assemble as a symmetrical dimer, forming the central body of FERRY (Fig. 1D). Each monomer adopts a Rossmann-like fold, where $6 \beta$-strands and $6 \alpha$ helices alternate. Through dimerization a continuous 12-stranded twisted $\beta$-sheet encased by two layers of $\alpha$-helices is formed which is a typical feature of dimeric enoyl reductases. The Nterminal part of Fy-4 is homologous to the catalytic domain of enoyl reductases. However, whereas Fy-4 is equipped with the full set of catalytic residues for enzymatic activity, the 
location in the center of the complex with helices of Fy-2 blocking the substrate binding site argues against such a catalytic activity when bound in the FERRY complex.

The arm-like appendages of FERRY are formed by a 6-helix bundle of Fy-2 each and a Fy-5 dimer (Fig. 1B-D). The Fy-2 molecules embrace the central Fy-4 dimer and dimerize at their $\mathrm{N}$ - and C-terminal ends as coiled-coils, of which only the stem is resolved to high resolution (Fig. 1B-D). The unique architecture of FERRY, which is likely intimately linked to its function as mRNA transport vehicle, does not resemble any of the other large Rab effector complexes, suggesting that FERRY represents a novel class of multi-protein Rab5 effector complex.

\section{Fy-2 serves as central scaffolding protein}

Fy-2 adopts an integral position within the FERRY complex, as it directly interacts with all other subunits. In the FERRY core, Fy-2 connects Fy-4 and Fy-5 and thereby acts as a scaffold for assembly of the whole protein complex (Fig. 2A, B). The 6-helix bundle of Fy-2 (aa 246-498) is folded in such a way that its antiparallel $\alpha$-helices form a $5 \mathrm{~nm}$-long hollow tube (Fig. 2A).

The interaction of Fy-2 with Fy-5 is mediated by the 6-helix bundle (Fig. 2C). Similar to Fy-4, Fy-5 contains a Rossmann-like fold, composed of a central 6-stranded $\beta$-sheet surrounded by six $\alpha$-helices, and dimerization of Fy-5 results in a continuous 12-stranded twisted $\beta$-sheet (Fig. 1D). The proximal and distal Fy-5 subunits bind to helices 4-5 and 2-3 of the 6-helix bundle, respectively, and form a relatively planar interface (Fig. 2B, C). Interestingly, although the 6-helix bundle is non-symmetrical, the interface between the Fy-5 dimer and the 6-helix bundle has a pseudo-two-fold symmetry (Fig. 2C, Fig. S5). The interaction between Fy-5 and the 6-helix bundle of Fy-2 is dominated by charge complementarity (Fig. 2D). While Fy-2 is enriched in positively charged residues at the interface, Fy-5 features a negatively charged patch. These findings are further corroborated by 
HDX-MS studies showing reduced deuterium exchange in the Fy-2 binding region of Fy-5 as well as in most of the corresponding binding regions of Fy-2 (Fig. 2E, Fig. S6).

To find out if the interaction of Fy-5 with Fy-2 alters its conformation, we compared our $2.7 \AA$ crystal structure of Fy-5 with Fy-5 in the cryo-EM structure (Fig. 2F, Table S2). Similar to the cryo-EM structure of the complex, Fy-5 formed symmetric dimers and the structure of the major part of the protein was identical (RMSD: $0.812 \AA$, Fig. 2F). However, the Fy-2 binding region of Fy-5 (aa 152-184) was rotated in-plane by $\sim 40^{\circ}$. Interestingly, this rotation happens in both subunits, so that the dimer stays symmetric and increases the binding interface between the two proteins.

The regions flanking the 6-helix bundle (aa 226-245 and aa 512-540) closely interact with the Fy-4 dimer by wrapping it with extended linkers, including a prominent vertical helix (Fig. 2A, B). Both linkers localize either to clefts or grooves at the protomer-protomer interface of the Fy-4 dimer forming tight interactions based on charge as well as shape complementarity (Fig. 3A, B). This complementarity is particularly prominent in the C-terminal linker where it even extends all the way to the start of the C-terminal coiled-coil domain. A striking feature of the interface between the N-terminal linker and Fy-4 are two electrostatic clusters with up to three different subunits participating. The first cluster comprises Lys-225 and Glu-224 from one Fy-2 molecule, Asp-230 of the second Fy-2 and Lys-299 of Fy-4 (Fig. 3B). The second cluster is formed by Lys-232 of Fy-2 and Asp-306, Glu-309 and Lys-310 of Fy-4.

The tight interaction between Fy-2 and Fy-4 becomes also evident from HDX-MS measurements (Fig. 3C, Fig. S6). Except for residues 237 to 250, for which no peptides were detected, all parts of Fy-2 that are in close contact with Fy-4 showed a decrease in deuterium uptake in the presence of Fy-4, indicating lower accessibility upon complex formation. The same is true for regions forming the binding clefts of Fy-4.

To more closely investigate the effect of Fy-2 binding to Fy-4, we crystallized the Fy-4 dimer in the absence of Fy-2, solved its structure at $2.9 \AA$ resolution and compared it with our 
cryo-EM structure of the complex (Fig. 3D, E, Table S2). While the overall structural similarity is high (RMSD: $0.766 \AA$ ), we observed two major differences between the two structures. First, the loop of Fy-2 (aa 293-297) moves slightly sideways to accommodate the vertical helix of Fy-4 upon complex formation (Fig. 3D). The second and more striking difference occurs in the region 225-239 of Fy-4, located close to the C-terminal coiled-coil of Fy-2. Here, a previously flexible loop of Fy-4 moves towards Fy-2 to form an additional interface, thereby strengthening the interaction between the two molecules (Fig. 3E).

The N- and C-terminal regions of the two Fy-2 subunits, namely upstream of aa 226 and downstream of aa 540, engage with their respective counterpart to form elongated coiled-coil structures that extend from the complex in diametrically opposite directions. However, the absence of a clear density for the majority of the coiled-coils in our structure indicates flexibility of these domains.

\section{Role of the two terminal coiled-coils of Fy-2}

Our cryo-EM structure revealed the architecture of the FERRY complex core, in which Fy-2 plays a key role as central scaffolding protein. However, two complex subunits, namely Fy-1 and Fy-3, were not resolved in the cryo-EM structure. Data from integrated protein-protein interaction network tools such as STRING indicated a close spatial and functional connection between the proteins (Szklarczyk et al., 2015). To identify the position of the two subunits within the complex, we performed HDX-MS measurements in the presence and absence of various complex subunits (Fig. 4A, Fig. S6). This allowed us to narrow down the binding region of Fy-1 and Fy-3 to residues 646-705 of Fy-2, which is located in its C-terminal coiled-coil. Furthermore, differential deuterium uptake profiles in the presence and absence of the small GTPase Rab5 allowed us to delineate the Rab5 binding region on the FERRY complex. Like Ferry 1/3, it is located on the C-terminal coiled-coil of Fy-2, but a bit closer to the C-terminus (aa 728-752). In known structures of Rab5/Rab5-effector complexes, including that of 
Rabaptin-5 and EEA1, Rab5 binds via its switch and inter-switch regions either directly to coiled-coils or to regions in their proximity (Mishra et al., 2010; Zhu et al., 2004). Indeed, the identified Rab5 binding region in the FERRY complex is predicted to form a parallel coiledcoil, further corroborating our HDX data (Fig. 4A, B, Fig. S6).

In our cryo-EM structure we could only identify density corresponding to the first residues of the C-terminal coiled-coil region of Fy-2 (Fig. 1B, Fig. S2, 5). This suggests a high flexibility of the rest of the coiled-coil, which is a common observation also for other coiledcoil-containing complexes (Shi et al., 2020). In general, long coiled-coils without a rigidifying interaction partner are mostly flexible and thus challenging to visualize in EM. To visualize the C-terminal coiled-coil region as well as the Fy-1 and Fy-3 subunits, we performed low-angle platinum shadowing experiments with the FERRY complex and extended hierarchical clustering of selected initial cryo-EM FERRY classes (Fig. 4C, Fig. S7, Movie S1). In the former analysis, we observed particles with two rod-like protrusions emanating from opposite sides of the FERRY core (Fig. 4C, Fig. S7). These protrusions probably correspond to the two terminal coiled-coil regions of Fy-2. The extended classification of the cryo-EM data revealed a rod-like density and a globular density that can be attributed to the coiled-coil and possibly to the Fy-1/3 subunits, respectively (Fig. 4C, Fig. S7, Movie S1).

In the case of the N-terminal coiled-coil of Fy-2, we observed only density corresponding to the beginning of the coiled-coil at high-resolution (Fig. 1B, Fig. S2, 5), similar to its C-terminal counterpart. However, at lower thresholds and in particular in 2D class averages we could also identify density in the space between the two arm-like appendages (Fig. 4D). This density can be unambiguously identified as a coiled-coil structure which adopts multiple orientations relative to the FERRY core (Fig. 4D, Movie S2). This also explains the lower resolution in this region of the complex (Fig. S4). Therefore, we calculated a reconstruction of the FERRY complex without applying symmetry, yielding a $6.2 \AA$ map (Fig. 4E, Fig. S2-4). Although the resolution of the coiled-coil did not improve and still appeared 
only at a lower threshold, its rod-like appearance including a twist is reminiscent of a coiledcoil. We believe that the proximal Fy-5 molecules bound to the arm restrict the overall mobility of the N-terminal coiled-coil of Fy-2 (Fig. 4F). The functional implications of this restricted degree of movement, however, are not yet understood. Taken together, our results show that both terminal coiled-coil domains of Fy-2 have different degrees of flexibility and act as a binding hub for other FERRY subunits. This even further underpins the central role of Fy-2 in the FERRY complex, as it directly interacts with all other four members of the complex as well as with Rab5.

\section{Interaction of FERRY with mRNA}

A protein structure comparison using the DALI server found several members of the DJ-1/ThiJ/PfpI superfamily to have a similar structure to Fy-5. Interestingly, DJ-1, which shares the Rossmann-like fold and overall structure with Fy-5 (RMSD: $1.012 \AA$, Fig. S5), has been shown to bind RNA at nanomolar concentrations and mutations in the corresponding gene have been linked to neuronal degeneration (Lee et al., 2003; van der Brug et al., 2008). The close structural similarity between both proteins suggests that Fy-5 could perform a similar function, i.e. RNA binding, in the FERRY complex. Electrophoretic motility shift assays, however, have shown that while the FERRY complex directly interacts with mRNA, Fy-5 alone is not capable of binding mRNA (Schuhmacher et al., 2021). We can envisage two possible explanations, either that Fy-5 is not involved in mRNA interaction, or the interaction interface is more complex and involves different subunits of the FERRY complex. In order to resolve this question, we performed UV-induced protein-RNA crosslinking mass spectrometry (Kramer et al., 2014) (Fig. 5A, SI File 1). The mass spectrometry analysis revealed in total 37 lysine residues within Fy-1 to Fy-5 crosslinked to RNA (SI File 1). Only two of the crosslinked lysine residues are found in one loop region of Fy-5 (Fig. 5A). Unexpectedly, most crosslinks cluster along the coiled-coils of Fy-2 instead. This suggests that bound RNA stretches over the whole 
length of the FERRY complex or that several RNA molecules bind simultaneously to the same FERRY complex at different positions. Interestingly, several crosslink sites are located in the cavity of the clamp-like structure in the FERRY complex, suggesting that this clamp plays an important role in mRNA binding (Fig. 5A). Consistent with the crosslinking data, the bottom of the cavity is lined by positively charged residues which are known to be essential for the interaction of proteins with RNA (Fig. 5B) (Ghaemi et al., 2017; Lunde et al., 2007).

Together, these results demonstrate that although Fy-5 is part of a complex mRNA binding interface on the FERRY complex, the majority of interactions are mediated by the coiled-coils of Fy-2.

\section{Hydrophobic cavity in the 6-helix bundle of Fy-2}

The 6-helix bundle of Fy-2 is a rather uncommon structural feature, connecting Fy-4 with the Fy-5 dimer (Fig. 6A). To our surprise, we identified an elongated density within the 6helix bundle, located at its Fy-4-facing side (Fig. 6B). While the exterior of the 6-helix bundle is mostly polar, its interior is highly enriched with hydrophobic residues (Fig. 6B, C). This suggests that the elongated density, which is centered almost perfectly within the hydrophobic cavity, i.e. residing on the central tube axis, probably corresponds to a hydrophobic molecule. When we analyzed the arrangement of the six helices that constitute the tube in more detail, we observed a change in their organization along the central axis (Fig. 6D). Starting from a hexagonal pattern on the Fy-4-facing side, they transition en route towards a more pyramidallike arrangement on the opposite end. This rearrangement is accompanied by a gradual decrease of the intraluminal diameter of the tube. Consequently, the putative molecule could not access the tube from the 'pyramidal' side unless major rearrangement occurred in the 6-helix bundle. To enter from the Fy-4-facing side therefore appears to be the more likely scenario, but would still require the displacement of one or more nearby loop regions of the 6-helix bundle, i.e. IL1 and/or IL-2, in order to grant access to the hydrophobic interior. The implications of this 
unidentified molecule on the function of the FERRY complex are not immediately obvious and represent a compelling topic for further investigations.

\section{Discussion}

In this study, we resolved the core of the FERRY complex to $4.0 \AA$ resolution using single particle cryo-EM. The structure is composed of a central Fy-4 dimer of which two arms, each consisting of a Fy-2 molecule and a Fy-5 dimer, protrude in different directions. In the scaffold protein Fy-2, both terminal regions interact with their symmetry-related counterpart to form flexible coiled-coils that extend in opposite directions. Furthermore, HDX measurements allowed us to delineate the binding sites of the subunits Fy-1 and Fy-3 as well as Rab5, all of which are located on the C-terminal coiled-coil of Fy-2.

The cryo-EM structure in combination with corresponding HDX-MS data provides important insights into the architecture of the FERRY complex and the interaction between its five subunits. Although the structural and functional record is by no means complete for the long-distance RNA transport via EEs, we can use the information provided by our atomic model of the FERRY complex to define critical steps in the process and suggest the following mode of FERRY recruitment and loading (Fig. 7). Activated EE-associated Rab5 recruits the FERRY complex through binding to the C-terminal coiled-coil region of Fy-2 to the EE (Fig. 7A). The Rab5 binding site locates adjacent to the Fy-1 and Fy-3 subunits, which also bind to the Cterminal coiled-coil region. Since there is no obvious additional binding site for EE proteins on FERRY, we believe that the elongated complex sits with its long axis at $90^{\circ}$ to the EE surface, although it should be borne in mind that the connection of the Rab5 globular domain to the membrane is not likely to be rigid due to the poorly ordered long hypervariable domain of the GTPase C-terminus in the absence of further interactions. Mutations in Fy-1 cause intellectual disability and severe infantile syndromic encephalopathy in patients, both characterized by brain atrophy, highlighting its importance in FERRY-mediated RNA-transport (Bhoj et al., 
2016; Chong et al., 2016). In general, perturbations in FERRY-mediated long-range RNA transport, which is particularly relevant to neurons, typically manifest in brain disorders. As for Fy-1, mutations in Fy-3 have been linked to intellectual disability, based on genetic analysis of two Finnish and one Dutch family (Philips et al., 2017).

In a 2018 study, the homozygous nonsense variant c.2089C>T (p.Arg697*), which results in a truncated Fy-2 protein that lacks the last 84 residues was identified in a patient with developmental delay and brain abnormalities (Suleiman et al., 2018). These 84 C-terminal residues on Fy-2 contain the Rab5 as well as Fy-1/3 binding sites, resulting in a failure of FERRY to bind to EE via Rab5, further underlining the importance of these subunits for the proper action of FERRY-mediated RNA transport.

Our crosslinking mass spectrometry measurements demonstrated that RNA binds primarily to the coiled-coils of Fy-2, as well as a loop of Fy-5, indicating that it stretches over the entire length of the FERRY complex or that several RNA molecules bind to different positions of the same FERRY complex. The composite binding interface, comprising different FERRY subunits, might be necessary to create different binding specificities for various mRNA transcripts in vivo. The three-dimensional arrangement of possible RNA-binding sites likely determines the specificity and binding affinity of certain RNA molecules. Accordingly, electrophoretic motility shift assays showed that the binding affinities to FERRY varied between different RNA transcripts (Schuhmacher et al., 2021).

For Fy-2, several mutations connected to malfunction of the brain have been described including four biallelic loss of function variants that have been linked to neurodevelopmental syndrome (Rehman et al., 2019). For Fy-5, the point mutation P166S has been associated with gastric adenocarcinoma (https://cancer.sanger.ac.uk). This particular mutation is located in the Fy-2 binding region of Fy-5 and could hence interrupt complex formation. So far, no mutations have been described for Fy-4. There is the possibility that this protein, despite its central position in the FERRY complex is not essential for FERRY function. This is supported by 
phylogenetic studies that have shown that Fy-4 is missing in FERRY complexes from lower organisms, such as insects and nematodes (Schuhmacher et al., 2021).

The structure of the FERRY core resembles that of an RNA-binding clamp, which raises the question whether this structure has mechanical implications. We observed a certain level of flexibility in the arms of the clamp in cryo-EM (Fig. S4, Movies S1, 2) indicating that the structural movements necessary for slight opening and closing of the clamp are possible. In addition, the N-terminal coiled-coil of Fy-2 is to a certain degree flexible which could facilitate the binding of the RNA by providing space inside the clamp. However, we propose that rather than mechanically clamping the RNA, the adaptable large three-dimensional cavity of the clamp provides the optimal binding site for structurally flexible RNAs. The quite long coiledcoils of Fy-2 provide additional binding sites for RNA, thereby increasing the specificity and/or affinity for the cargo (Fig. 7B). Alternatively, multiple RNA transcripts can bind simultaneously to the same FERRY complex (Fig. 7C). Although we demonstrated that RNA binds directly to FERRY, we cannot exclude that additional adaptor proteins are involved in this process in vivo. The long N-terminal coiled-coil of Fy-2 would provide enough space for their binding.

Another question that arises is the function of the density that we identified in the hydrophobic pocket formed by the 6-helix bundle of Fy-2. Due to the hydrophobic environment, we assume that the density corresponds to a hydrophobic molecule. However, based on the shape of the density and its unknown occupational state in the structure, we cannot distinguish whether it is a lipid or single fatty acid/aliphatic chain. We can exclude that it is detergent or a similar amphipathic compound since these were not added during purification. It is also very unlikely that it is a post-translational modification. First of all, there would be no space for a modifying enzyme. In addition, Leu-333, Thr-335 and Val-332 which are in close proximity to the ends of the density are non-typical residues for lipidic modifications. 
Although highly speculative, it is conceivable that the hydrophobic cavity might accommodate the lipidic tail of prenylated Rab5 and could thus act similar to other GDIs, i.e. facilitating the transport of Rab5 through the cytosol. In this way, another layer of regulation of Rab5 activity could be theoretically achieved by the FERRY complex. Since we have not co-purified Rab5 with the FERRY complex, we assume that in our case the binding pocket is occupied by a hydrophobic molecule that was inserted during the recombinant expression.

Taken together, our structural analyses of FERRY extend the understanding of this remarkable Rab5 effector complex and hence also shed light onto how intracellular mRNA transport processes are coordinated within the cell, serving as a basis for future research. 


\section{Material and Methods}

\section{Molecular cloning}

The human proteins Fy-1 (Tbck, ENSG00000145348, Q8TEA7), Fy-2 (Ppp1r21, ENSG00000162869, Q6ZMI0), Fy-3 (C12orf4, ENSG00000047621, Q9NQ89), Fy-4 (Cryzl1, ENSG00000205758, O95825), Fy-5 (Gatd1, ENSG00000177225, Q8NB37) and Rab5a (ENSG00000144566, P20339) were used in vectors as described (Schuhmacher et al., 2021). Fy-4 and Fy-5 were expressed with a not-cleavable N-terminal hexa-histidine (His 6 ) tag in bacteria and insect cells, respectively. Fy-1, Fy- 2 and Fy-3 were combined in multi-gene plasmid with Fy-1 carrying a N-terminal His 6 tag and produced in insect cells. Rab5 was used as GST fusion variant in a pGEX-6P-3 vector.

\section{Virus production and insect cell expression}

SF9 cells growing in ESF921 media (Expression Systems) were co-transfected with linearized viral genome and the expression plasmid and selected for high infectivity. P1 and P2 viruses were generated according to the manufacturer's protocol. Best viruses were used to infect SF9 cells at $10^{6}$ cells $/ \mathrm{mL}$ at $1 \% \mathrm{vol} / \mathrm{vol}$ and routinely harvested after $40-48$ hours at about $1.5 \times 10^{6}$ cells $/ \mathrm{ml}$. The pellet was suspended in lysis buffer (20 mM HEPES, pH 8.0, $250 \mathrm{mM} \mathrm{NaCl}, 20$ $\mathrm{mM} \mathrm{KCl}, 20 \mathrm{mM} \mathrm{MgCl} 2$ and $40 \mathrm{mM}$ imidazole) or SEC buffer (20 mM HEPES, pH 7.5, 250 $\mathrm{mM} \mathrm{NaCl}, 20 \mathrm{mM} \mathrm{KCl}$ and $20 \mathrm{mM} \mathrm{MgCl}$ ) supplemented with a protease inhibitor cocktail, flash frozen in liquid nitrogen and stored at $-80{ }^{\circ} \mathrm{C}$.

\section{Protein expression and purification}

The FERRY complex, its individual components Fy-4 and Fy-5 and Rab5 were expressed and purified as described in (Schuhmacher et al., 2021). For better readability a brief description of the expression and purification is given in the following. 
In general, purified proteins were analyzed using SDS-PAGE and their concentration determined by spectrophotometry (NanoDrop Lite, Thermo Scientific) unless stated otherwise. Fy-5: Fy-5 was expressed in E. coli BL21 (DE3) (company) under autoinduction conditions using D-(+)-lactose monohydrate at $1.75 \%(\mathrm{w} / \mathrm{v})$, supplemented with respective antibiotics (50 $\mu \mathrm{g} / \mathrm{mL}$ kanamycin or $100 \mu \mathrm{g} / \mathrm{mL}$ ampicillin) at $30{ }^{\circ} \mathrm{C}$. Harvested bacteria were suspended in lysis buffer and subsequently lysed or stored at $-80{ }^{\circ} \mathrm{C}$. After lysis (sonication) Fy-5 was purified from the clarified lysate in a two-step purification, involving Ni-NTA affinity chromatography (HisTrap FF column, GE Healthcare) and size exclusion chromatography (SEC) (HiLoad 16/600 Superdex 200 pg, GE Healthcare) in SEC buffer.

Fy-4: After sonication and clarification of the lysate by centrifugation (22 $500 \mathrm{rpm} / 61236 \mathrm{x} \mathrm{g}$, $20 \mathrm{~min}, 4^{\circ} \mathrm{C}$ ), the lysate was filtrated using Millex ${ }^{\circledR}$ HV membrane filter units with a pore size of $0.45 \mu \mathrm{m}$ (Merck Millipore). Fy-4 was subsequently purified combining Ni-NTA affinity chromatography (HisTrap FF column, GE Healthcare) and SEC (HiLoad 16/600 Superdex 200 pg, GE Healthcare).

FERRY complex: To reconstitute the FERRY complex, Fy-1 to Fy-3 were expressed from a single virus and the harvested insect cells supplemented with purified Fy-4 and Fy-5 prior to cell lysis (Microfluidizer LM20, Microfluidics). The purification was accomplished by a twostep protocol combining affinity chromatography and SEC. After clarification (22 $500 \mathrm{rpm} / 61$ $236 \mathrm{x} \mathrm{g}, 20 \mathrm{~min}, 4^{\circ} \mathrm{C}$ ) and filtration (Millex ${ }^{\circledR} \mathrm{HV}$ membrane filter units), the lysate was supplemented with Ni-NTA agarose (Qiagen, $1.3 \mathrm{ml}$ resin/ 11 insect cell pellet). Subsequently, the resin was transferred into gravity flow chromatography columns (Poly-Prep ${ }^{\circledR}$ Chromatography Column, Bio-Rad) and extensively washed with lysis buffer and wash buffer (20mM HEPES, $\mathrm{pH} 7.5,250 \mathrm{mM} \mathrm{NaCl}, 20 \mathrm{mM} \mathrm{KCl}, 20 \mathrm{mM} \mathrm{MgCl}_{2}$ and $80 \mathrm{mM}$ imidazole). The complex was eluted with elution buffer (20 mM HEPES, pH 7.5, $250 \mathrm{mM} \mathrm{NaCl}, 20 \mathrm{mM} \mathrm{KCl}$, $20 \mathrm{mM} \mathrm{MgCl}_{2}$ and $500 \mathrm{mM}$ imidazole) in $1 \mathrm{ml}$ fractions and protein containing fractions were 
applied to SEC without further concentration using a Superose 6 increase (Superose 6 Increase 10/300 GL, GE Healthcare) which were equilibrated in SEC buffer.

Rab5: Expression of GST-Rab5 was performed under autoinduction conditions as described for Fy-5. Harvested bacterial pellets were resuspended in SEC buffer, lysed using sonication and the lysate clarified by centrifugation (22 $\left.500 \mathrm{rpm} / 61236 \mathrm{x} \mathrm{g}, 20 \mathrm{~min}, 4{ }^{\circ} \mathrm{C}\right)$. GST-Rab5 was captured on Glutathione Sepharose 4B resin (Cytiva), extensively washed with SEC buffer and cleaved off the resin using HRV $3 \mathrm{C}$ protease (produced in house). The protein was subsequently concentrated using Amicon Ultracel-30K (Millipore) centrifuge filters and applied to SEC using a Superdex 200 column (HiLoad 16/600 Superdex 200 pg, GE Healthcare) equilibrated in SEC buffer.

Rab5 was loaded with GTPYS prior to the HDX experiments. To do so, Rab5 was concentrated using an Amicon Ultracel-30K (Millipore) centrifuge filter, subsequently supplemented with $2.5 \mathrm{mM}$ GTPYS and $250 \mathrm{nM}$ of a GST fusion of the Rab5 GEF domain of Rabex5 and incubated for 60 mins on ice. To remove the Rab5 GEF domain, Glutathione Sepharose 4B was added to the mixture and incubated for 90 mins at $4{ }^{\circ} \mathrm{C}$. The resin was pelleted by centrifugation $(12000$ $\mathrm{rpm} / 15300 \mathrm{x} \mathrm{g}, 10 \mathrm{~min}, 4^{\circ} \mathrm{C}$ ) and the supernatant containing the GTPYS loaded Rab5 was flash frozen and stored at $-80{ }^{\circ} \mathrm{C}$. The protein concentration was determined using a BCA assay (Pierce ${ }^{\mathrm{TM}}$ BCA Protein Assay Kit, Thermo Scientific).

\section{Crystallization of Fy-4 and Fy-5}

All crystallization experiments were carried out by the sitting-drop method in SWISSCI MRC 2-well crystallization plates at room temperature with a reservoir volume of $50 \mu 1$ and a drop volume of $3 \mu \mathrm{l}$, using a 1:1 mixture of protein and crystallization solution. Initial crystals of Fy-5 were obtained from a $15 \mathrm{mg} / \mathrm{ml}$ solution after 4-6 weeks in 0.1 M MES, pH 5.0, $0.8 \mathrm{M}$ Ammonium sulfate. Fy-4 crystals were grown from a $12 \mathrm{mg} / \mathrm{ml}$ solution after 3-5 days in 0.1 M MES pH 6.0, 5 \% (w/v) PEG 3000 and $30 \%$ (w/v) PEG 200. 


\section{Data collection, structure determination and analysis}

Crystals were flash-frozen in liquid nitrogen after a short incubation in a cryo-protecting solution composed of mother-liquor supplemented with $20 \%(\mathrm{v} / \mathrm{v})$ glycerol. Data collection was performed at the European Synchrotron Radiation Facility (ESRF) in Grenoble, France under cryogenic conditions at the beamline: ID30a-3. Data were recorded with an EIGER X 4M detector. Diffraction data was processed using XDS (Kabsch, 2010) and the CCP4implemented program SCALA (Winn et al., 2011). The structures of Fy-4 and Fy-5 were solved by molecular replacement (MR) with CCP4-integrated PHASER (McCoy et al., 2007). APC35852, a member of the DJ superfamily (pdb: 1u9c) was used as search model for Fy-5 and the $\mathrm{NADP}^{+}$bound version of human zeta-crystallin (pdb: 1yb5) was used as search models to solve the structure of Fy-4. The structures were manually built in COOT (Emsley et al., 2004) and refined using PHENIX refine (Adams et al., 2010).

\section{Hydrogen-Deuterium Exchange Mass Spectrometry}

HDX-MS was performed as previously described (Lauer et al., 2019; Mayne et al., 2011; Walters et al., 2012). Proteins $(120 \mu \mathrm{L}$ of $0.5 \mathrm{uM})$ are diluted $6: 4$ with $8 \mathrm{M}$ urea, $1 \%$ trifluoroacetic acid, passed over an immobilized pepsin column $(2.1 \mathrm{~mm}$ x $30 \mathrm{~mm}$, ThermoFisher Scientific) in $0.1 \%$ trifluoroacetic acid at $15{ }^{\circ} \mathrm{C}$. Peptides are captured on a reversed-phase C8 cartridge, desalted and separated by a Zorbax 300SB-C18 column (Agilent) at $1{ }^{\circ} \mathrm{C}$ using a $5-40 \%$ acetonitrile gradient containing $0.1 \%$ formic acid over $10 \mathrm{~min}$ and electrosprayed directly into an Orbitrap mass spectrometer (LTQ-Orbitrap XL, ThermoFisher Scientific) with a T-piece split flow setup (1:400). Data were collected in profile mode with source parameters: spray voltage $3.4 \mathrm{kV}$, capillary voltage $40 \mathrm{~V}$, tube lens $170 \mathrm{~V}$, capillary temperature $170{ }^{\circ} \mathrm{C} . \mathrm{MS} / \mathrm{MS}$ CID fragment ions were detected in centroid mode with an AGC target value of 104. CID fragmentation was 35\% normalized collision energy (NCE) for $30 \mathrm{~ms}$ 
at Q of 0.25 . HCD fragmentation NCE was $35 \mathrm{eV}$. Peptides were identified using Mascot (Matrix Science) and manually verified to remove ambiguous peptides. For measurement of deuterium uptake, $12 \mu \mathrm{L}$ of $5 \mu \mathrm{M}$ protein was diluted in SEC buffer prepared with deuterated solvent. Samples were incubated for varying times at $22{ }^{\circ} \mathrm{C}$ followed by the aforementioned digestion, desalting, separation and mass spectrometry steps. The intensity weighted average $\mathrm{m} / \mathrm{z}$ value of a peptide's isotopic envelope was compared plus and minus deuteration using the HDX workbench software platform (Pascal et al., 2012). Individual peptides were verified by manual inspection. Data were visualized using Pymol. Deuterium uptake was normalized for back-exchange when necessary by comparing deuterium uptake to a sample incubated in $6 \mathrm{M}$ urea in deuterated buffer for $12-18 \mathrm{~h}$ at room temperature and processed as indicated above.

\section{UV-light induced protein-RNA crosslinking}

The purified FERRY complex was reconstituted with mrp141 mRNA in equimolar amounts at $37{ }^{\circ} \mathrm{C}$ for $1 \mathrm{~h}$ in $20 \mathrm{mM}$ HEPES pH 7.5, $250 \mathrm{mM} \mathrm{NaCl}, 20 \mathrm{mM} \mathrm{KCl}, 20 \mathrm{mM} \mathrm{MgCl} 2$. For reconstitution, the RNA/FERRY complex concentration was adjusted to $400 \mathrm{nM}$. Aliquots containing $125 \mathrm{pmol}$ of the complex were UV-irradiated $(\lambda=254 \mathrm{~nm})$ on ice for $10 \mathrm{~min}$ in an in-house built crosslinking apparatus following ethanol-precipitation (Kramer et al., 2014). Further sample processing was performed as described with minor modifications (Kramer et al., 2014). Briefly, the protein-RNA pellet was dissolved in $4 \mathrm{M}$ urea, $50 \mathrm{mM}$ Tris/ $\mathrm{HCl}, \mathrm{pH} 7.5$ by sonication. For RNA digestion, the sample was diluted to $1 \mathrm{M}$ urea with $50 \mathrm{mM}$ Tris/ $\mathrm{HCl}$, pH 7.5 and $10 \mu \mathrm{g}$ RNase A (EN0531, Thermo Fisher Scientific) and 1kU RNase T1 (EN0531, Thermo Fisher Scientific) were added following incubation at $37^{\circ} \mathrm{C}$ for $4 \mathrm{~h}$. Proteins were digested over night at $37^{\circ} \mathrm{C}$ with trypsin (V5111, Promega) at a 1:20 enzyme to protein mass ratio. Sample cleanup was performed using C18 columns (74-4601, Harvard Apparatus) according to the manufacturers' instructions and crosslinked peptides were enriched with $\mathrm{TiO} 2$ 
columns (in-house; Titansphere $5 \mu \mathrm{m}$; GL Sciences), as described (Kramer et al., 2014). Peptide-(oligo)nucleotides were dried and subjected to LC-ESI-MS/MS.

\section{LC-ESI-MS/MS and data analysis}

Enriched peptide-(oligo)nucleotides were dissolved in $2 \%$ [v/v] acetonitrile, $0.05 \%$ [v/v] TFA. LC-MS/MS analyses were performed on an Orbitrap Exploris 480 (Thermo Fisher Scientific) instrument coupled to a nanoflow liquid chromatography system (Thermo Scientific Dionex Ultimate 3000). Sample separation was performed over $58 \mathrm{~min}$ at a flow rate of $300 \mathrm{nl} / \mathrm{min}$ using $0.1 \%[\mathrm{v} / \mathrm{v}]$ formic acid (buffer A) and 80\% [v/v] acetonitrile, $0.08 \%[\mathrm{v} / \mathrm{v}]$ formic acid (buffer B) and a linear gradient from $10 \%$ to $45 \%$ buffer B in 44 min. Eluting peptide(oligo)nucleotides were analyzed in positive mode using a data-dependent top 30 acquisition method. Resolution was set to 120,000 (MS1) and 30,000 FWHM (MS2). AGC targets were set to 1e6 (MS1) and 1e5 (MS2), normalized collision energy to $28 \%$, dynamic exclusion to $10 \mathrm{~s}$, and maximum injection time to 60 (MS1) and $120 \mathrm{~ms}$ (MS2). Measurements were performed twice for the first technical replicate and once for second and third technical replicate. MS data were analyzed and manually validated using the OpenMS pipeline RNPxl and OpenMS TOPPASViewer (https://www.openms.de/, Version 2.6.0) (Kramer et al., 2014). We note that $\mathrm{U}-\mathrm{H}_{2} \mathrm{O}$ cannot be distinguished from $\mathrm{C}-\mathrm{NH}_{3}$ as both these RNA adducts have the same monoisotopic masses. Hence, in SI file 1 crosslinked nucleotides are listed as U$\mathrm{H}_{2} \mathrm{O} / \mathrm{C}-\mathrm{NH}_{3}$.

\section{Rotary Shadowing}

Low-angle metal shadowing and electron microscopy was performed as described previously (Huis In 't Veld et al., 2016). In brief, freshly purified FERRY complexes were diluted 1:1 with spraying buffer (200 $\mathrm{mM}$ ammonium acetate and $60 \%$ glycerol) to a concentration of approximately $0.5 \mu \mathrm{M}$ and air-sprayed onto freshly cleaved mica pieces (V1 quality, Plano 
$\mathrm{GmbH}$ ). Specimens were mounted and dried in a MED020 high-vacuum metal coater (Bal-tec). A platinum layer of approximately $1 \mathrm{~nm}$ and a $7 \mathrm{~nm}$ carbon support layer were subsequently evaporated onto the rotating specimen at angles of $7^{\circ}$ and $45^{\circ}$, respectively. $\mathrm{Pt} / \mathrm{C}$ replicas were released from the mica on water, captured by freshly glow-discharged 400 -mesh $\mathrm{Pd} / \mathrm{Cu}$ grids (Plano $\mathrm{GmbH}$ ), and visualized using a $\mathrm{LaB}_{6}$ equipped JEM-1400 transmission electron microscope (JEOL) operated at $120 \mathrm{kV}$. Images were recorded at a nominal magnification of 60,000x on a 4k x 4k CCD camera F416 (TVIPS), resulting in $0.189 \mathrm{~nm}$ per pixel. Particles with discernible coiled-coil extensions were manually selected.

\section{Sample vitrification}

For sample preparation in cryo-EM, 3.5 $\mu \mathrm{L}$ of purified FERRY complex at a concentration of $0.7 \mathrm{mg} / \mathrm{mL}$ was applied to freshly glow-discharged UltrAuFoil 1.2/1.3 grids (Quantifoil), automatically blotted for $3 \mathrm{~s}$ and plunged into liquid ethane using the a Vitrobot (Thermo Fisher Scientific), operated at $100 \%$ humidity and $13{ }^{\circ} \mathrm{C}$. Individual grid quality was screened prior to data collecting using a Talos Arctica transmission electron microcope (TEM, Thermo Fisher Scientific), operated at $200 \mathrm{KV}$. Prior to data collection, grids were stored in liquid nitrogen.

\section{Cryo-EM data acquisition}

Cryo-EM data set of the FERRY complex was collected on a Titan Krios TEM (Thermo Fisher Scientific), equipped with an $\mathrm{C}_{\mathrm{s}}$-Corrector and in-column energy filter, operated at an acceleration voltage of $300 \mathrm{kV}$. Micrographs were recorded on a K2 direct electron detector (Gatan) with a final pixel size of $1.08 \AA$ in counting mode. A total of 40 frames (with $375 \mathrm{~ms}$ and $1.895 \mathrm{e}^{-} / \AA^{2}$ each) was recorded during each exposure, resulting in a total exposure time of $15 \mathrm{~s}$ and an overall electron dose of $75.8 \mathrm{e}^{-/} \AA^{2}$. Automated data collection was done with the help of the software EPU (Thermo Fisher Scientific) and monitored in real time using 
TranSPHIRE (Stabrin et al., 2020). A total of 1879 micrographs was collected with a defocus range between $-1.6 \mu \mathrm{m}$ and $-2.8 \mu \mathrm{m}$ and an energy filter width of $20 \mathrm{eV}$.

\section{Image processing and 3-D reconstruction}

Initially, micrographs were inspected visually to discard images with high-drift and icecontamination. Using MotionCor2, operated in $3 \times 3$ patch mode, individual frames were aligned and summed (Zheng et al., 2017). In this step, unweighted and dose-weighted full-dose images were calculated. Image processing was performed with the SPHIRE software package (Table S1) (Moriya et al., 2017). Values for the defocus and astigmatism of unweighted fulldose images were determined using CTFFIND4 (Rohou and Grigorieff, 2015). A flowchart of the image processing strategy is described in Fig. S3. First, particles were automatically selected based on a trained model with the help of crYOLO (Wagner et al., 2019). After extraction of the particles with a window size of $264 \times 264$, the resulting stack was further classified using the iterative and stable alignment and clustering (ISAC) algorithm, implemented in SPHIRE. This yielded a stack of $18.5 \mathrm{k}$ particles of dose-weighted drift-corrected particles. Based on a subset of class averages produced by ISAC, the $a b$ initio 3D structure determination program RVIPER in SPHIRE calculated an initial intermediate resolution 3D structure that served as reference in the subsequent 3D refinement (MERIDIEN). This 3D refinement step, in which C2 symmetry was imposed, yielded a $5.9 \AA$ map of the core of the FERRY complex, estimated by the 'gold standard' 0.143 criterion of the Fourier shell correlation (FSC). Based on the obtained 3D parameters, particles were re-centered, followed by re-extraction, resulting in $18.3 \mathrm{k}$ particles. 3D refinements with $\mathrm{C} 2$ symmetry and without applying symmetry yielded 3D reconstruction with resolutions of 4.6 and $6.2 \AA$, respectively. In the next step, iterative cycles of Bayesian particle polishing in RELION (Scheres, 2012) and 3D refinement in SPHIRE (Moriya et al., 2017) were performed. The particles of this 'polished' stack were further subjected to another round of 3D refinement in SPHIRE with imposed C2 symmetry. Here, the 
real space filtering according to signal-to-noise ratio (SNR) algorithm, named SIDESPLITTER, was applied to reduce overfitting (Ramlaul et al., 2020). This resulted in a final 4.0 Å electron density map of the FERRY complex.

In general, the global resolution of maps was calculated between two independently refined half maps at the 0.143 criterion. Local resolutions were calculated with LOCALRES in SPHIRE. EM density maps were either filtered according to global resolution or using the local de-noising filter L-AFTER (Ramlaul et al., 2019). In the latter case, which is also based on half maps, features with more signal than noise are better recovered.

\section{Model building, refinement and validation}

To build the model for the (Fy-4) $)_{2}(\mathrm{Fy}-2)_{2}(\mathrm{Fy}-5)_{4}$ core of the FERRY complex, the obtained crystal structures of Fy-4 and Fy-5 were initially fitted into the corresponding density using the rigid body fitting tool in Chimera (Pettersen et al., 2004). trRosetta, a de novo protein structure prediction algorithm that is based on direct energy minimization with restrained Rosetta, was used to obtain initial models for Fy-2 (Yang et al., 2020). The predicted model for the 6-helix bundle domain, containing residues 246 to 498, that matched our experimental density best was subsequently fitted similarly to Fy-4 and Fy-5 using rigid body fit. Manual model building for the regions $\mathrm{N}$ - and C-terminal 6-helix bundle, which comprise residues 218 - 245 and 499 552 , respectively, was further guided by secondary structure predictions of individual trRosetta runs for these regions, which include the vertical helix as well as the beginning of the two terminal coiled-coils of Fy-2. With the resulting combined model, containing residues 2-349, 218-552 and 8-217 of Fy-4, Fy-2 and Fy-5, respectively, a restrained refinement in PHENIX was performed (Liebschner et al., 2019). In the next step, the model was further refined using a combination of manual building in COOT and real-space refinement in PHENIX (Emsley et al., 2004; Liebschner et al., 2019). Geometries of the final model were either obtained from 
PHENIX or calculated using Molprobity (http://molprobity.biochem.duke.edu). Refinement and model building statistics are summarized in Table S1.

\section{Hierarchical classification of 2-D classes}

Separate hierarchical classifications were run for classes selected from ISAC (Yang et al., 2012). Aligned particles from each class were generated using the SPHIRE program sp_eval_isac.py (http://sphire.mpg.de/wiki/doku.php?id=pipeline:utilities:sp_eval_isac). Particles for each class were then subjected to multivariate data analysis and hierarchical classification in SPIDER (Frank et al., 1996; Shaikh et al., 2008). Binary masks for correspondence analysis were drawn manually onto class averages using e2display.py from EMAN2 (Tang et al., 2007), and then thresholded in SPIDER using the operation 'TH M'. Hierarchical classification using Ward's method was performed using SPIDER operation 'CL HC'. Class averages were visualized by the Python script binarytree.py which uses SPIDER's SPIRE libraries (Baxter et al., 2007). Spider procedures can be found at the SPIDER web site (https://spider.wadsworth.org/spider_doc/spider/docs/techs/MSA/index.html).

\section{Structure analysis and visualization}

UCSF Chimera was used for structure analysis, visualization and figure preparation (Pettersen et al., 2004). The angular distribution plots as well as beautified 2-D class averages were calculated in SPHIRE (Moriya et al., 2017).

\section{Acknowledgments}

We thank O. Hofnagel and D. Prumbaum for assistance with EM data collection, M. Stabrin for lively discussions regarding image processing and M. Raabe for help with MS of crosslinked samples. We also acknowledge R. Goody and A. Musacchio for valuable feedback regarding the manuscript. This work was supported by the Max Planck Society (to S.R., M.Z. and H.U.). 


\section{Author contributions}

J.S.S., S.R. and M.Z. designed the project. J.S.S. provided the protein complex and performed X-ray studies. J.S.S. and J.L. performed the hydrogen-deuterium exchange mass spectrometry experiments, L.M.W. and H.U. performed and analyzed crosslinking-MS experiments and P.J.H. performed low-angle platinum shadowing experiments. D.Q. prepared specimens, recorded, analyzed and processed the electron microscopy data and prepared figures. T.R.S. performed hierarchical classification analysis. D.Q. and B.U.K. built the atomic models. S.R. managed the project. D.Q. and S.R. wrote the manuscript with input from all authors.

\section{Competing interests}

The authors declare no competing financial interests.

\section{Data availability}

The cryo-EM density map of the FERRY complex is deposited into the Electron Microscopy Data Bank with the accession number EMD-xxxx. Model coordinates for the FERRY complex, the X-ray structures of Fy-4 and Fy-5 are available with the PDB entry IDs xxxx, xxxx and xxxx, respectively. 
bioRxiv preprint doi: https://doi.org/10.1101/2021.06.21.449265; this version posted June 22, 2021. The copyright holder for this preprint

(which was not certified by peer review) is the author/funder, who has granted bioRxiv a license to display the preprint in perpetuity. It is made available under aCC-BY-NC-ND 4.0 International license.

A)

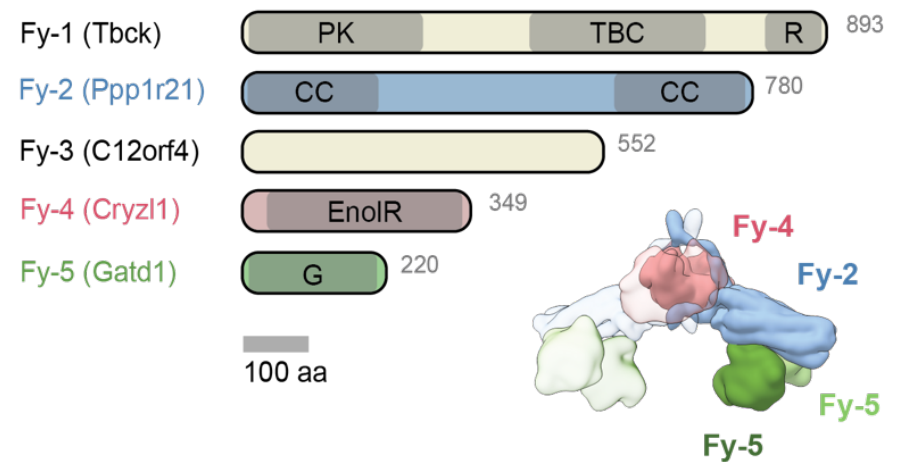

B)
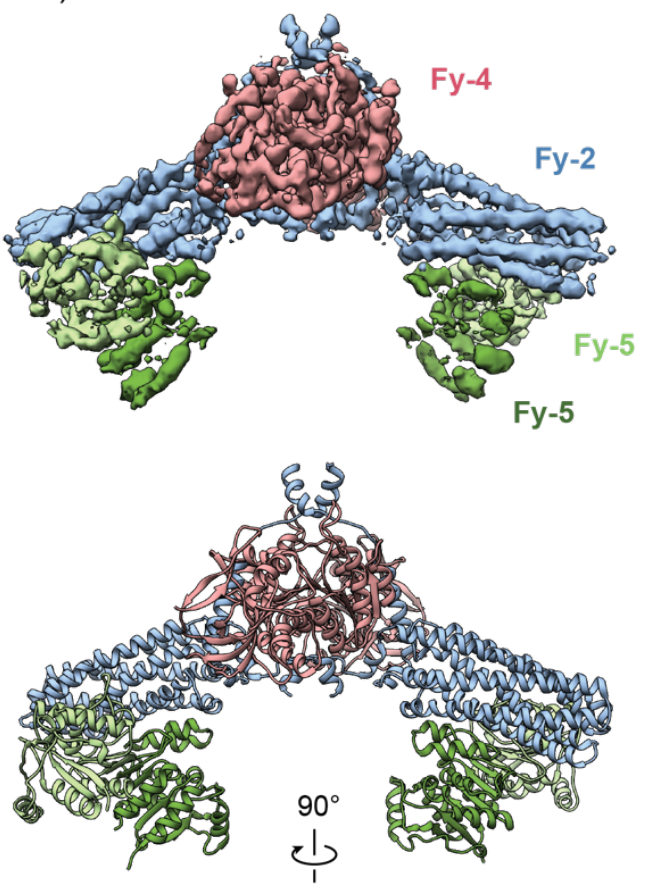

$180^{\circ} 90^{\circ}$
$1-2-$

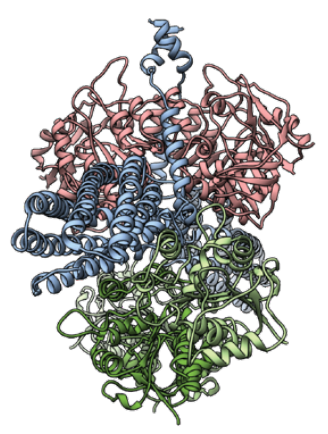

D)

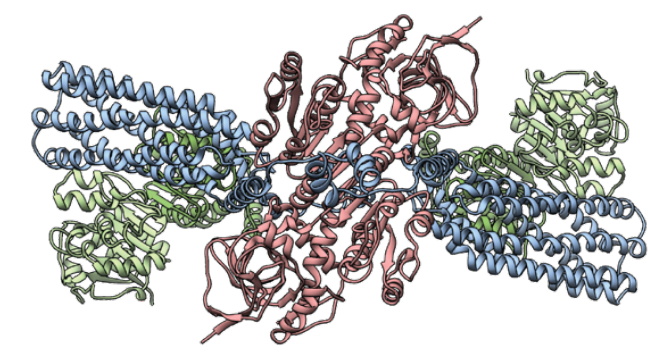

$90^{\circ}$

$-180^{\circ}$
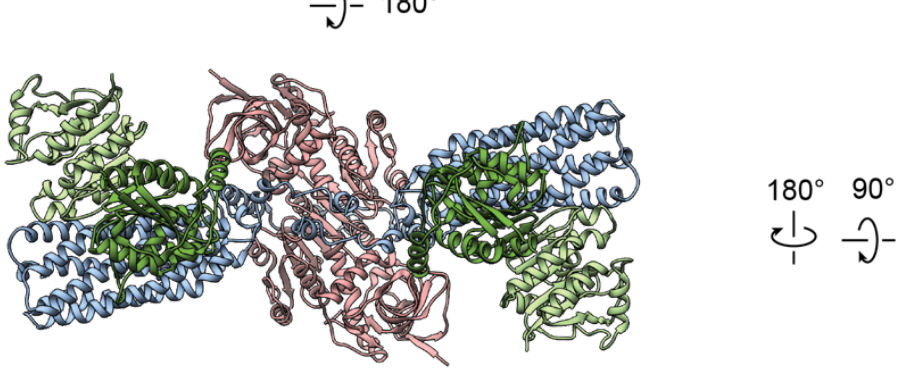
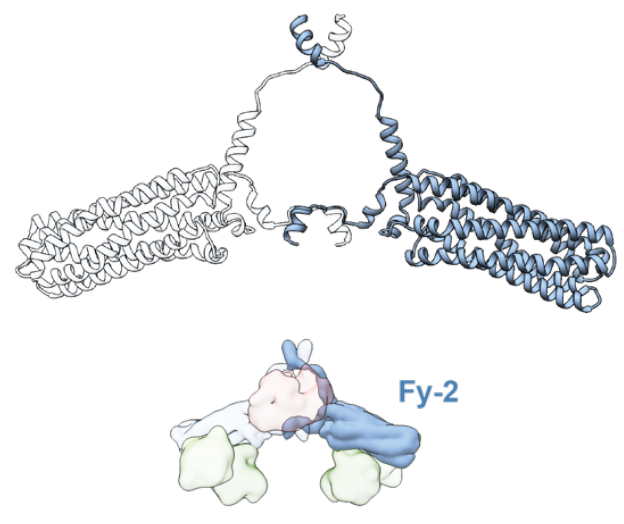

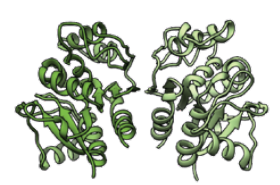

$90^{\circ}$

$-$

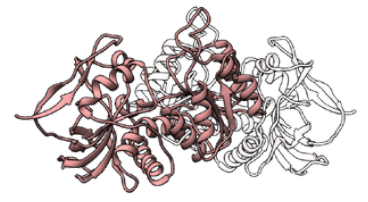

$90^{\circ}$

$-$
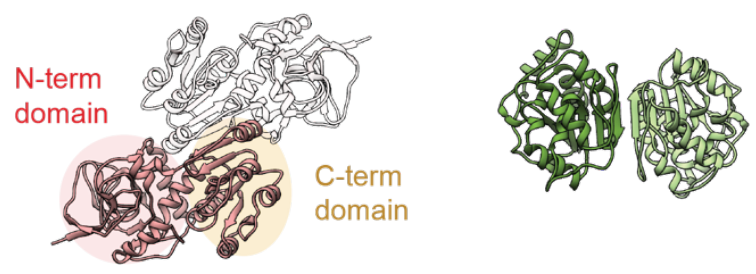

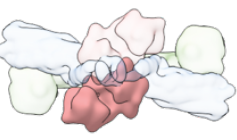

Fy-4

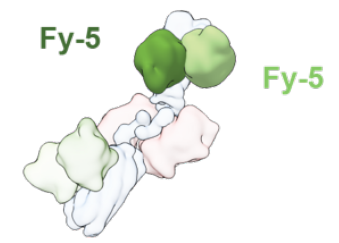


bioRxiv preprint doi: https://doi.org/10.1101/2021.06.21.449265; this version posted June 22, 2021. The copyright holder for this preprint (which was not certified by peer review) is the author/funder, who has granted bioRxiv a license to display the preprint in perpetuity. It is made available under aCC-BY-NC-ND 4.0 International license.

\section{Figure 1. Architecture of the FERRY complex.}

(A) Domain architecture of the individual subunits of the FERRYcomplex (top, left). A schematic representation of the FERRY core is shown on the bottom right with only one half of the symmetric complex highlighted. Note that the asymmetric part of the complex consists of one molecule of Fy-2 and Fy-4 as well as a dimer of Fy-5. Domain abbreviations: PK - Pseudokinase; TBC - Tre-2/Bub2/Cdc16; R - Rhodanese; CC - Coiled coil; EnolR - Enoyl reductase; G - GATase1-like domain.

(B) Color-coded segmented cryo-EM density map of the core of the FERRY complex, compromising Fy-2 (blue), Fy-4 (red) and Fy-5 (green). The C2-symmetric complex has a clamp-like three-dimensional shape with two arms (Fy-2, Fy-5) extending from a central body (Fy-4). To highlight the different positions of the two Fy-5 molecules in each arm, proximal and distal Fy-5 are colored in dark and light green, respectively.

(C) Rotated views of the atomic model of the FERRY complex with subunits colored according to (B).

(D) Rotated views of individual subunits of the FERRY core with Fy-2, Fy-4 and Fy-5 shown on the left, middle and right, respectively. In case of Fy-2 and Fy-4, the dimeric partner is indicated as transparent ribbon representation. The relative location within the complex is highlighted in the cartoon representation below.

See also Fig. S1-5 and Table S1, 2. 
bioRxiv preprint doi: https://doi.org/10.1101/2021.06.21.449265; this version posted June 22,2021 . The copyright holder for this preprint (which was not certified by peer review) is the author/funder, who has granted bioRxiv a license to display the preprint in perpetuity. It is made available under aCC-BY-NC-ND 4.0 International license.

A)

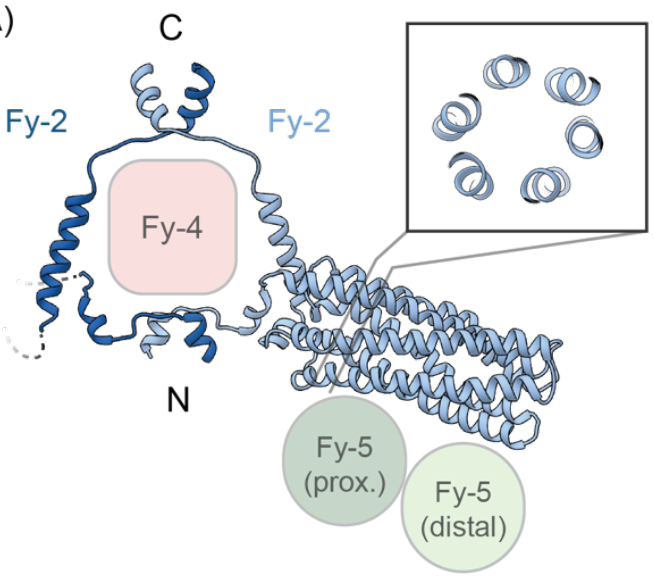

B)

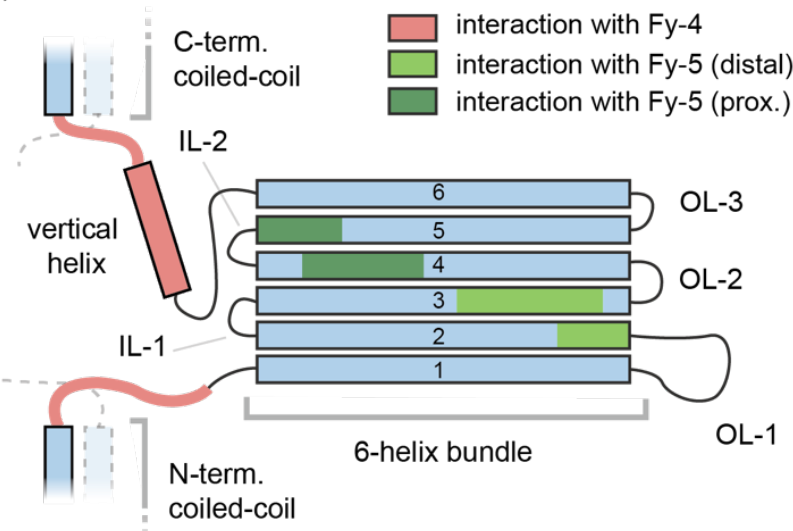

C)

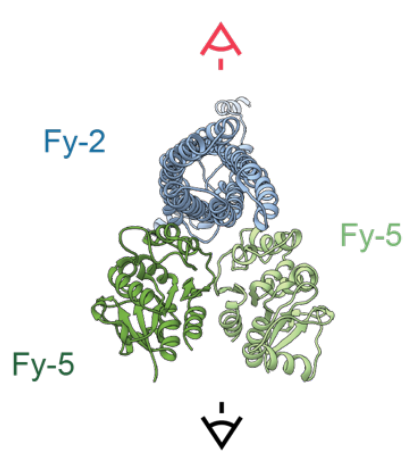

D)

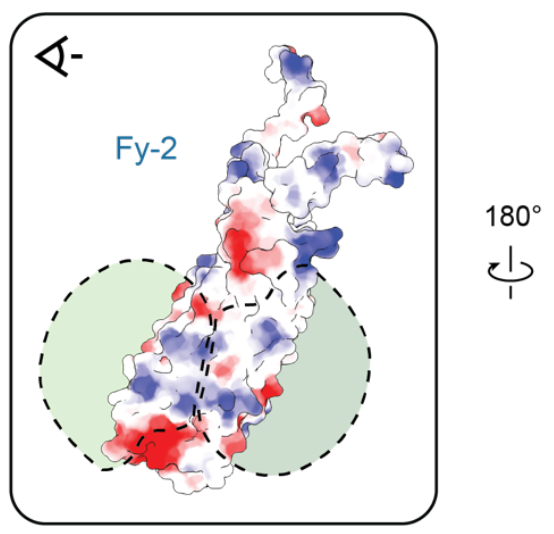

F)

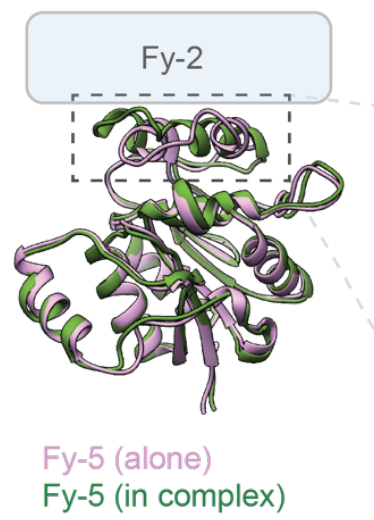

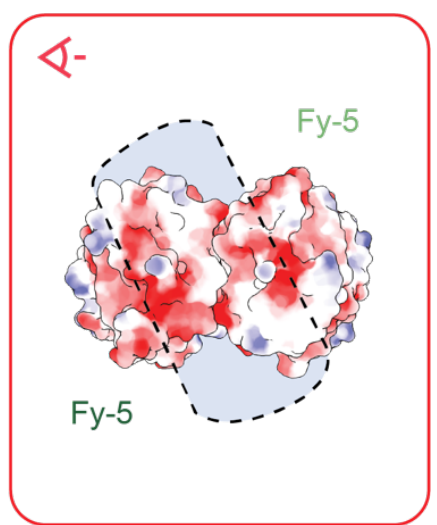

Fy-2

binding region

(aa 152-184)

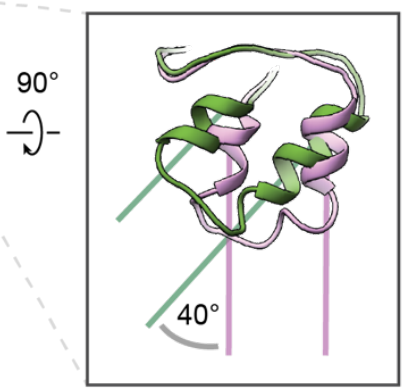

\section{Figure 2. Interaction of Fy-2 with Fy-5.}

(A) Fy-2 adopts an integral position within the FERRY core by interacting not only with the Fy-5 dimer and Fy-4, but it also dimerizes with the second Fy-2 subunit to form two coiled-coil regions. To easier distinguish between the two Fy-2 molecules, they are colored in dark and light blue hues. Notably, the two terminal coiled-coils of Fy-2 extend in opposite directions. The most characteristic feature of Fy-2 is its 6-helix bundle domain, connecting the two coiled coils. Inset shows a cross-section through the 6-helix bundle, highlighting the distinct hexagonal arrangement of the six helices in this region. Same color code as in Fig. 1.

(B) Topology diagram depicting the domain organization of Fy-2. Interaction regions are highlighted by respective colors.

(C) The Fy-5 dimer binds to the outer surface of the 6-helix bundle domain of Fy-2. Same color code as in Fig. 1 . (D) A bottom view, as indicated by the black eye in (C), is depicted on the left. The electrostatic surface of Fy-2 is shown and the position of the Fy-5 dimer indicated as dashed silhouette. In the corresponding $180^{\circ}$-rotated top view (right panel, red eye in $(\mathrm{C})$ ), the electrostatic surface of Fy-5 is presented with the position of Fy-2 indicated as dashed silhouette. The predominant positively charged surface of Fy-2 matches the complementary negatively charged surface of Fy-5 in their binding interface. 
bioRxiv preprint doi: https://doi.org/10.1101/2021.06.21.449265; this version posted June 22, 2021. The copyright holder for this preprint (which was not certified by peer review) is the author/funder, who has granted bioRxiv a license to display the preprint in perpetuity. It is made available under aCC-BY-NC-ND 4.0 International license.

(E) Interacting regions of Fy-2 and Fy-5 based on H-D exchange mass spectrometry are highlighted in dark blue and green, respectively. The planar binding surface of Fy- 5 exhibited lower deuterium exchange rates when bound to Fy-2, in which the complementary regions of its 6-helix bundle domain are less accessible.

(F) Superposition of the crystal structure of Fy-5 (pink) and proximal Fy-5 bound in the FERRY complex (green). Inset shows a rotated close-up of the Fy-2-binding region of Fy-5 in which an approx. $40^{\circ}$ in-plane rotation is observed upon binding to Fy-2.

See also Fig. S6. 
A)

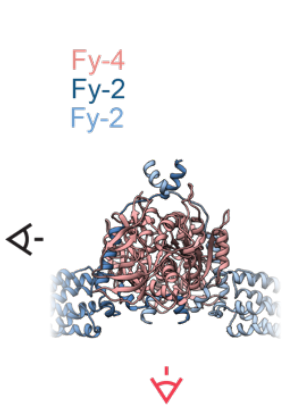

B)

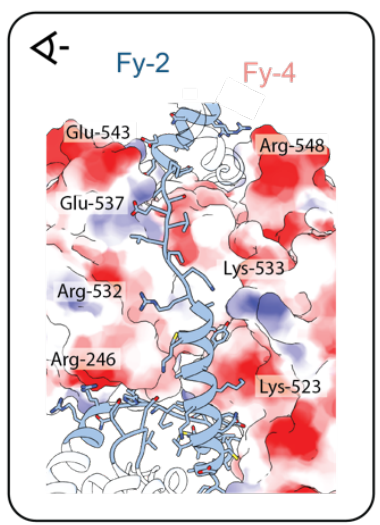

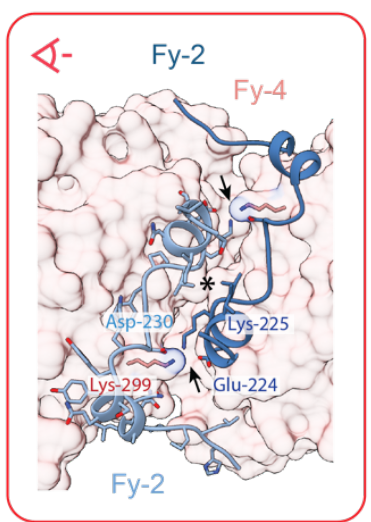

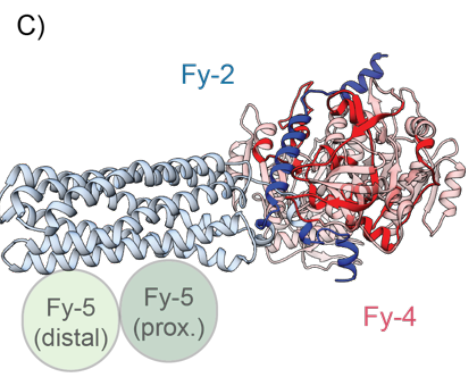

D)

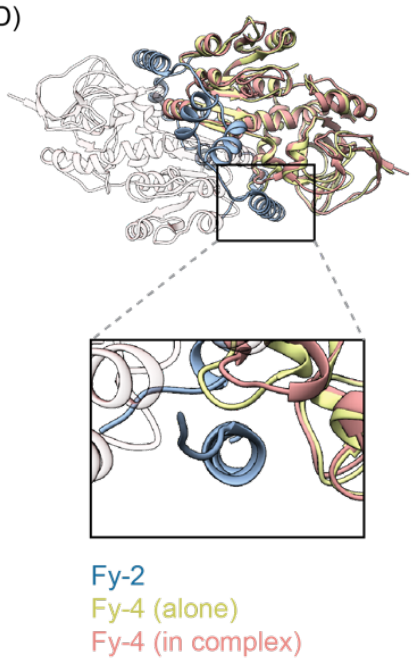

E)

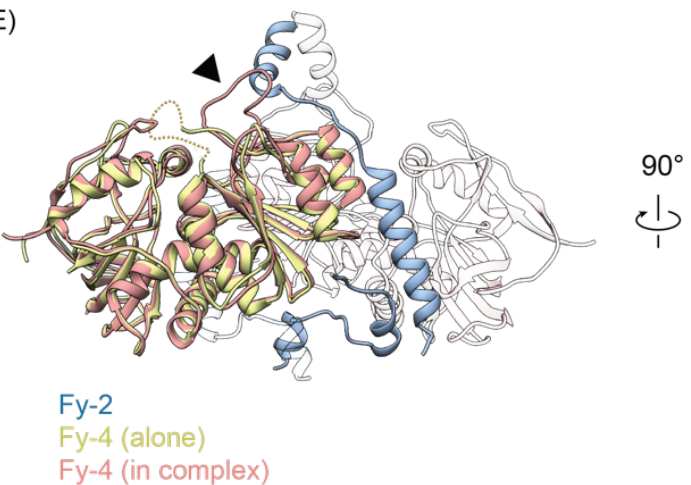

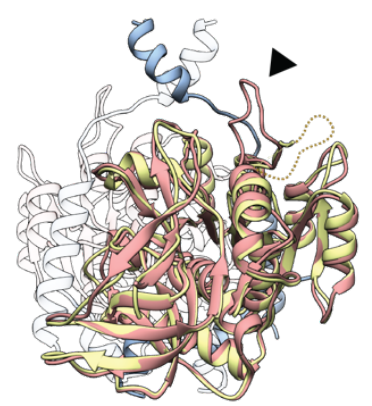

Fy-4 (in complex)

\section{Figure 3. Interaction of Fy-2 with Fy-4.}

(A) Fy-2 interacts with Fy-4 by wrapping around it, before dimerizing with the second Fy-2 to form coiled-coil regions.

(B) Close-up of the side view, indicated by black eye in (A), is depicted on the left. The Fy-4 dimer is presented as electrostatic surface, interacting parts of Fy-2 as blue ribbon. The vertical helix of Fy-2 is accommodated inside a cleft formed by the two Fy-4 molecules, binding to complementary-charged regions on the surface of Fy-4. A second close-up of the top view, indicated by a red eye in (A), is shown on the right.

Fy-4 dimer is shown as semi-transparent surface, Fy-2 as ribbon in light and dark blue with important residues highlighted. The beginning of the N-terminal coiled-coil domain of Fy-4 is highlighted by an asterisk. The complex is stabilized by two charged clusters (black arrows) that are flanking the coiled-coil, containing charged residues from both Fy-2 subunits as well as Fy-4, and by shape complementarity.

(C) Interacting regions of Fy-2 and Fy-4 based on H-D exchange mass spectrometry are highlighted in dark blue and red, respectively. In Fy-4, mostly regions that constitute the binding cleft for the vertical helix upon Fy-2 binding are not accessible for deuterium exchange. In the case of Fy-2, the vertical helix and regions wrapping around Fy-4 exhibit lower exchange rates.

(D) Top views of the superposition of the X-ray structure of Fy-4 (yellow) and Fy-4 bound in the FERRY complex (red). Inset shows a close-up of the binding cleft for the vertical helix of Fy-2 (blue), formed by the two Fy-4 protomers. Upon Fy-2 binding, a loop region of Fy-4 moves sideways to accommodate the vertical helix of Fy-2. (E) Rotated views of the superposition of the crystal structure of Fy-4 (yellow) and Fy-4 bound in the FERRY complex (red). When Fy-4 is bound in the complex, a previously disordered loop region, indicated as dotted line, becomes ordered (black arrow) and interacts with Fy-2.

See also Fig. S6. 
bioRxiv preprint doi: https://doi.org/10.1101/2021.06.21.449265; this version posted June 22,2021 . The copyright holder for this preprint (which was not certified by peer review) is the author/funder, who has granted bioRxiv a license to display the preprint in perpetuity. It is made available under aCC-BY-NC-ND 4.0 International license.

A)

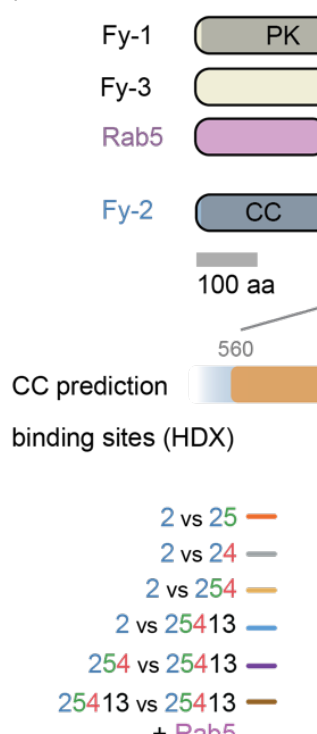

D)

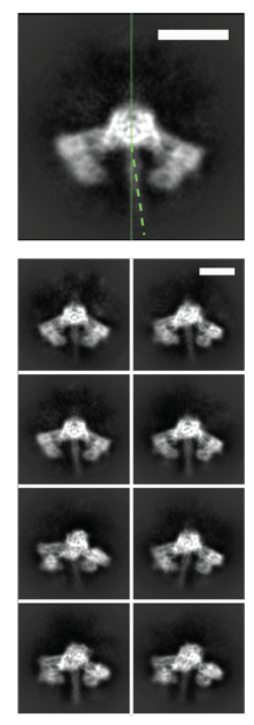

B)

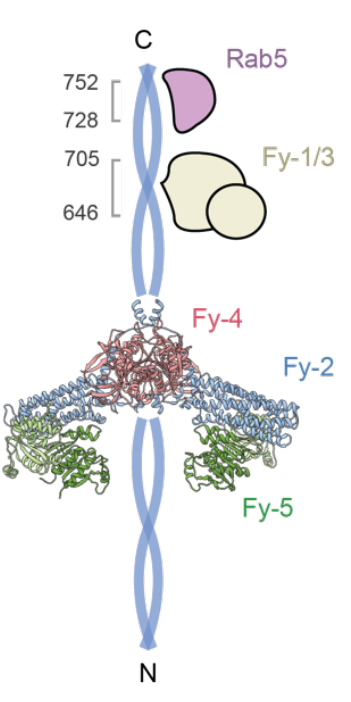

C)

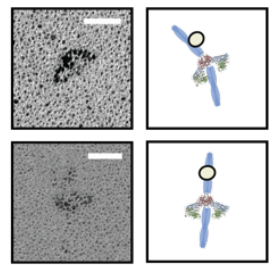

F)

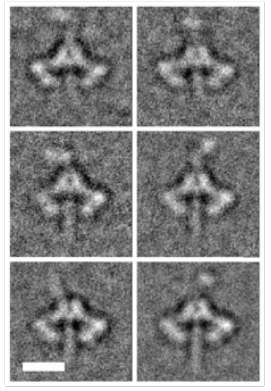

E)
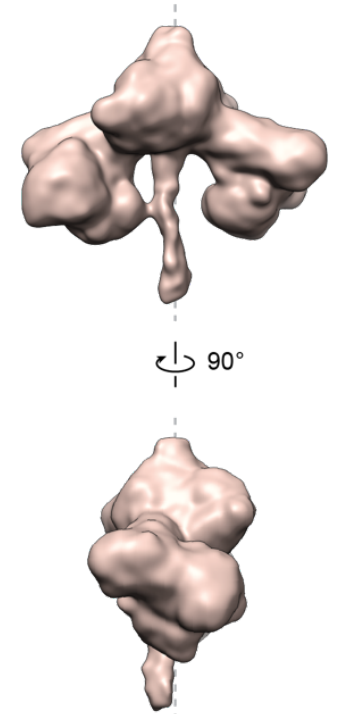

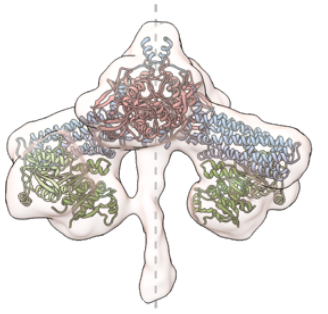

l) $90^{\circ}$

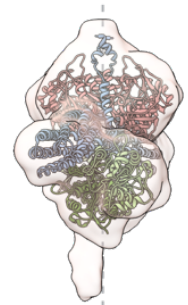

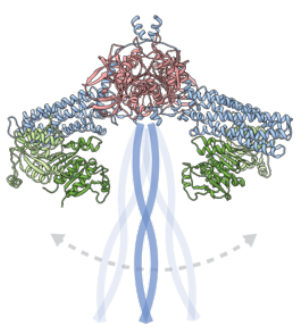

(1) $90^{\circ}$

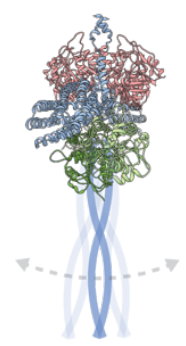

Figure 4. Terminal coiled-coil regions of Fy-2 extend in opposite directions.

(A) Domain architecture of the Fy-2-interacting proteins Fy-1, Fy-3 and Rab5 is provided at the top. Enlargement of the C-terminal domain of Fy-2 shows predicted coiled-coil regions with orange indicating high $\mathrm{CC}$ formation probability. Hydrogen-deuterium exchange mass spectrometry (HDX-MS) measurements delineate the binding regions of Fy-1/3 and Rab5 on the C-terminal coiled-coil of Fy-2. Notably, the Fy-1/3 binding site is in close proximity to the Rab5 binding site, which is located close to the C-terminus of Fy- 2 . Abbrevations: DDU differential deuterium uptake; see also schematic in (B).

(B) Schematic representation of the FERRY complex, displaying that both $\mathrm{N}$ - and C-terminal coiled-coil regions of Fy-2 extend in opposite directions from the FERRY core. Binding sites for Fy-1/3 and Rab5 are derived from HDX-MS data.

(C) FERRY complex visualized by electron microscopy after glycerol spraying and low-angle platinum shadowing is shown on the left with corresponding cartoon illustration provided on the right (upper panel). Two rod-like protrusions extend in opposite directions from the FERRY core. Scale bar: $20 \mathrm{~nm}$.

Selected 2D cryo-EM classes of FERRY after hierarchical classification shows density corresponding to the Cterminal coiled-coil region of Fy-2 located at the top of the complex (bottom panel). Scale bar: $10 \mathrm{~nm}$.

(D) Cryo electron microscopy 2-D class averages of the FERRY complex showing that the N-terminal coiled-coil of Fy-2 can adopt multiple position relative to the FERRY core. Scale bar: $10 \mathrm{~nm}$. 
bioRxiv preprint doi: https://doi.org/10.1101/2021.06.21.449265; this version posted June 22, 2021. The copyright holder for this preprint (which was not certified by peer review) is the author/funder, who has granted bioRxiv a license to display the preprint in perpetuity. It is made available under aCC-BY-NC-ND 4.0 International license.

(E) Rotated views of 3-D reconstruction of FERRY without applied symmetry, filtered to $15 \AA$. Right panel shows fitting of the atomic models for the FERRY core into the density for orientation. The elongated density that protrudes from the central Fy-4 dimer corresponds to the N-terminal coiled-coil of Fy-2. The deviation from the central complex axis suggests a certain degree of flexibility for the N-terminal coiled-coil.

(F) Schematic representation of the FERRY complex highlighting the flexible nature of the N-terminal coiled-coil of Fy-2. Both "arms" (6-helix bundle domain of Fy-2 and the Fy-5 dimer) appear to restrict the degree of movement.

See also Fig. S6, 7 and Movie S1, 2. 
bioRxiv preprint doi: https://doi.org/10.1101/2021.06.21.449265; this version posted June 22, 2021. The copyright holder for this preprint (which was not certified by peer review) is the author/funder, who has granted bioRxiv a license to display the preprint in perpetuity. It is made available under aCC-BY-NC-ND 4.0 International license.

A)

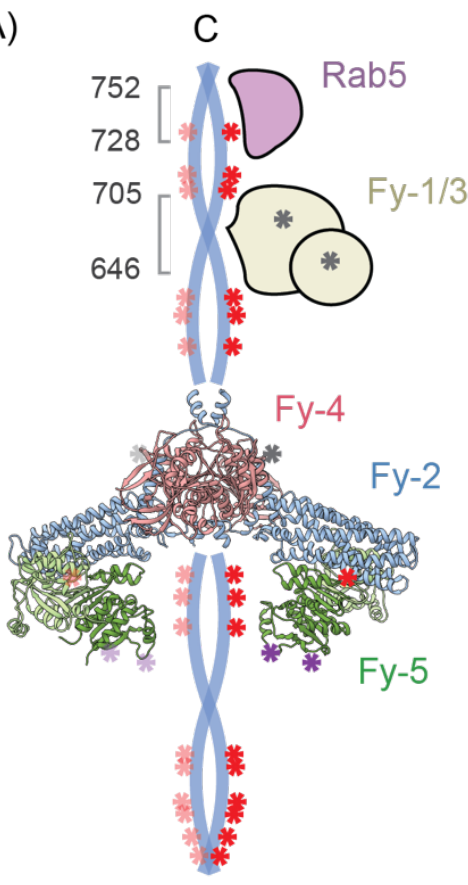

$\mathrm{N}$
PK

Fy-1 (Tbck)

Fy-2 (Ppp1r21)

Fy-3 (C12orf4)

Fy-4 (Cryzl1)

Fy-5 (Gatd1)

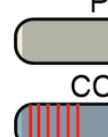

$\mathrm{CC}$

TBC

R 893

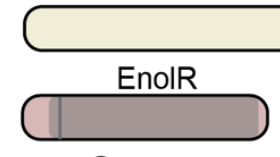

G

349
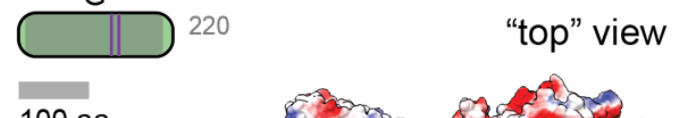

B)
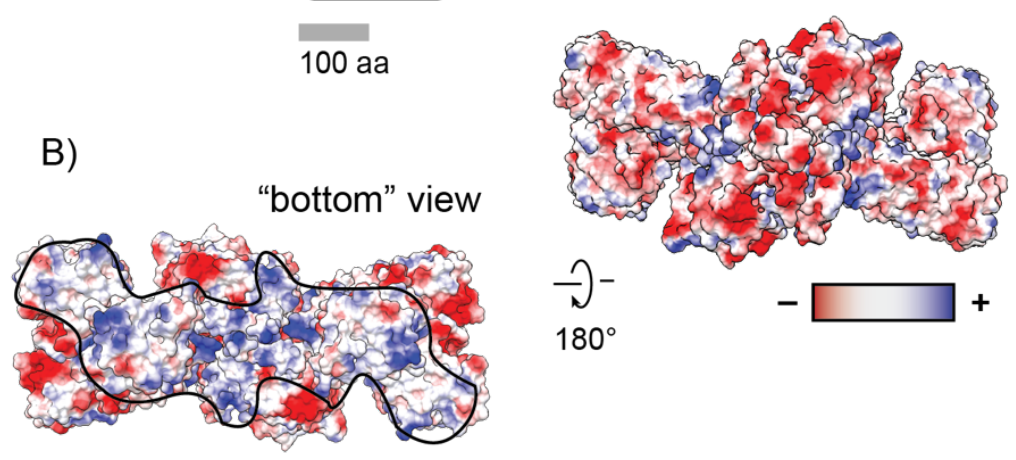

$180^{\circ}$

\section{Figure 5. RNA binding of the FERRY complex.}

(A) In the left panel, positions of UV cross-links between RNA/Fy-2 and RNA/Fy-5 are indicated in the FERRY complex by red and lilac asterisks, respectively. Crosslinks with RNA in the other FERRY subunits are indicated by grey asterisks. Only crosslinks are shown that were identified in at least 3 out of 5 replicates. Notably, crosslinks are enriched at the terminal coiled-coils of Fy-2. Together with Fy-5, the N-terminal coiled-coil of Fy-2 constitutes a clamp-like structure, which is important in RNA binding. In the right panel, the domain organization of FERRY subunits is depicted with positions of crosslinks indicated. Domain abbreviations: PK - Pseudokinase; TBC - Tre2/Bub2/Cdc16; R - Rhodanese; CC - Coiled coil; EnolR - Enoyl reductase; G - GATase1-like domain.

(B) Top- and bottom view of the electrostatic surface of the FERRY complex core. Interestingly, in contrast to the "top" side, the "bottom" side is lined with positively charged residues. Boundaries of patches are indicated by black line.

See also File S1. 
A)

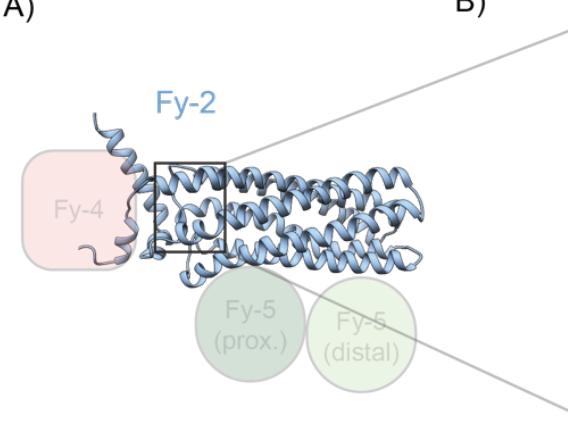

C)

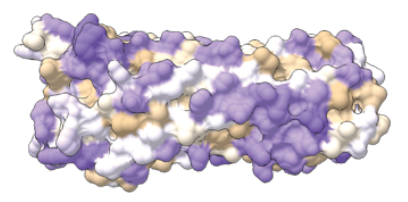

D)

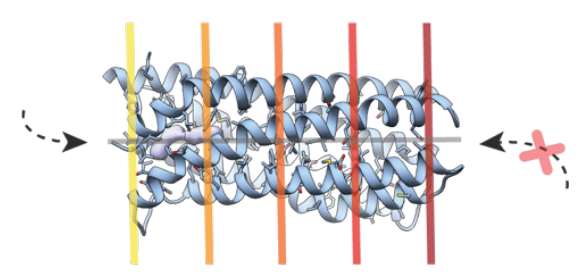

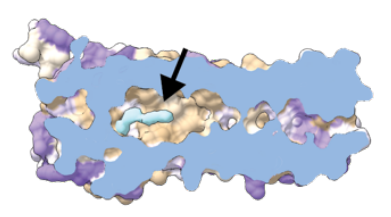

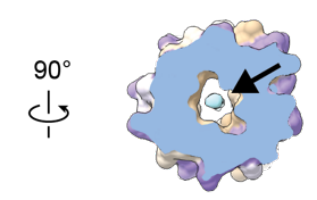

Hydrophilic

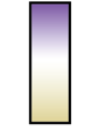

Hydrophobic

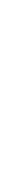

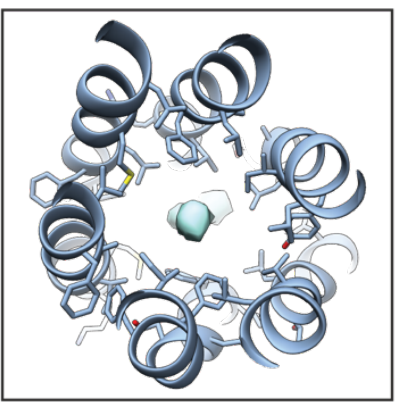

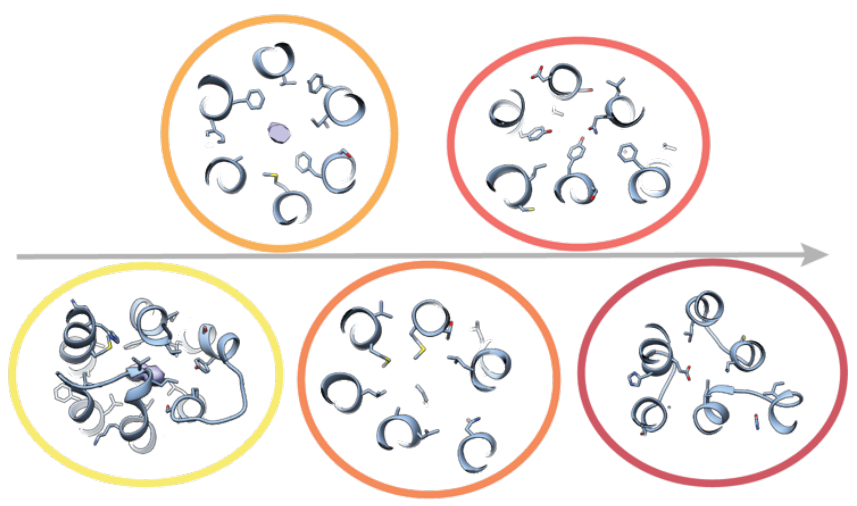

Figure 6. Hydrophobic binding pocket of FERRY.

(A) The 6-helix bundle domain of Fy-2 adopts a crucial position within the FERRY complex.

(B) The left inset shows an enlarged side view of the interior of the 6-helix bundle domain at the Fy-4-facing end of the tube, as indicated in (A). Both, 3D-reconstruction (semi-transparent) and fitted atomic model (blue) are shown. An additional, elongated density (cyan) is accommodated within the hollow cavity formed by the 6-helix bundle. A rotated view shown in the right panel further highlights the almost perfectly centered position of the cyan density as well as the hydrophobic environment that is created by inward-facing hydrophobic side chains.

(C) Surface hydrophobicity of the 6-helix bundle domain of Fy-2 is depicted on the left, showing that the cytoplasm-exposed exterior is primarily hydrophilic. Cross sections of different orientations in the middle and right panel highlight the hydrophobic nature of the interior cavity, with the position of the elongated density indicated by an arrow.

(D) Different color-coded cross sections of the 6-helix bundle domain of Fy-2 are shown in the right panel with their respective position along the central tube axis (grey) indicated in the left panel. The six helices transition from a more ordered hexagonal arrangement (yellow, closest to Fy-4) to a more pyramidal-like array (red, opposite end). This en route transition correlates with a decrease of the interior space, causing a narrowing of the cavity towards the distal end. 


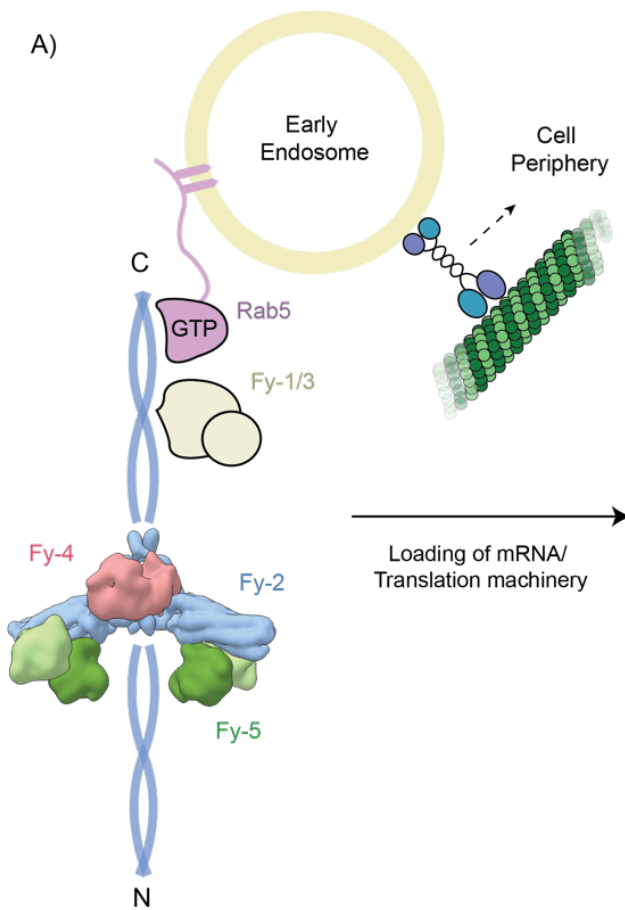

B)

B)

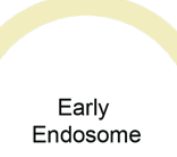

C

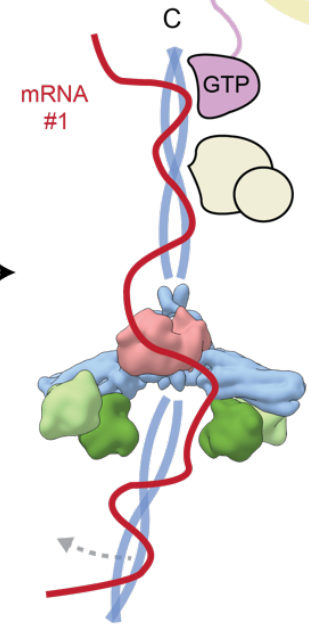

C)

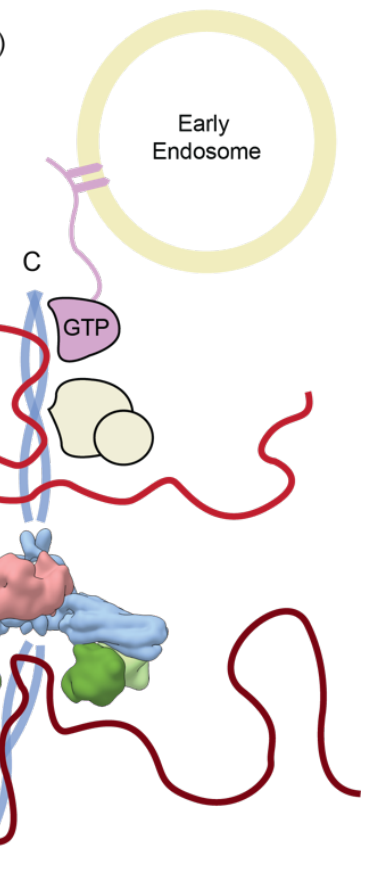

\section{Figure 7. Model of FERRY recruitment and RNA binding.}

(A) The activated GTP-bound form of Rab5 recruits the FERRY complex by binding to the C-terminal coiled-coil domain of Fy-2. Since Rab5 proteins insert via two C-terminal lipidated cysteines into the early endosome (EE) membrane, FERRY also becomes associated with the EE.

$(\mathbf{B}, \mathbf{C})$ Ferry interacts with mRNA and/or translation machinery. Here, either a single RNA molecule binds to the coiled-coils of Fy-2 (B) or multiple RNA transcripts bind simultaneously to the same FERRY complex $(\mathbf{C})$. The flexibility of the N-terminal coiled-coil might facilitate RNA binding via the FERRY clamp. 


\section{References}

Adams, P.D., Afonine, P.V., Bunkóczi, G., Chen, V.B., Davis, I.W., Echols, N., Headd, J.J., Hung, L.-W., Kapral, G.J., Grosse-Kunstleve, R.W., et al. (2010). PHENIX: a comprehensive Python-based system for macromolecular structure solution. Acta Crystallogr. D Biol. Crystallogr. 66, 213-221.

Baxter, W.T., Leith, A., and Frank, J. (2007). SPIRE: the SPIDER reconstruction engine. Journal of Structural Biology 157, 56-63.

Bhoj, E.J., Li, D., Harr, M., Edvardson, S., Elpeleg, O., Chisholm, E., Juusola, J., Douglas, G., Guillen Sacoto, M.J., Siquier-Pernet, K., et al. (2016). Mutations in TBCK, Encoding TBC1-Domain-Containing Kinase, Lead to a Recognizable Syndrome of Intellectual Disability and Hypotonia. The American Journal of Human Genetics 98, 782-788.

Bröcker, C., Kuhlee, A., Gatsogiannis, C., Balderhaar, H.J.K., Hönscher, C., Engelbrecht-Vandré, S., Ungermann, C., and Raunser, S. (2012). Molecular architecture of the multisubunit homotypic fusion and vacuole protein sorting (HOPS) tethering complex. Proc. Natl. Acad. Sci. U.S.a. 109, 1991-1996.

Bucci, C., Parton, R.G., Mather, I.H., Stunnenberg, H., Simons, K., Hoflack, B., and Zerial, M. (1992). The small GTPase rab5 functions as a regulatory factor in the early endocytic pathway. Cell 70,715-728.

Chen, P.-I., Kong, C., Su, X., and Stahl, P.D. (2009). Rab5 isoforms differentially regulate the trafficking and degradation of epidermal growth factor receptors. The Journal of Biological Chemistry 284, 30328-30338.

Chong, J.X., Caputo, V., Phelps, I.G., Stella, L., Worgan, L., Dempsey, J.C., Nguyen, A., Leuzzi, V., Webster, R., Pizzuti, A., et al. (2016). Recessive Inactivating Mutations in TBCK, Encoding a Rab GTPase-Activating Protein, Cause Severe Infantile Syndromic Encephalopathy. The American Journal of Human Genetics 98, 772-781.

Chou, H.-T., Dukovski, D., Chambers, M.G., Reinisch, K.M., and Walz, T. (2016). CATCHR, HOPS and CORVET tethering complexes share a similar architecture. Nature Structural \& Molecular Biology 23, 761-763.

Christoforidis, S., McBride, H.M., Burgoyne, R.D., and Zerial, M. (1999). The Rab5 effector EEA1 is a core component of endosome docking. Nature 397, 621-625.

Cioni, J.-M., Lin, J.Q., Holtermann, A.V., Koppers, M., Jakobs, M.A.H., Azizi, A., Turner-Bridger, B., Shigeoka, T., Franze, K., Harris, W.A., et al. (2019). Late Endosomes Act as mRNA Translation Platforms and Sustain Mitochondria in Axons. Cell 176, 56-.

De Vos, K.J., and Hafezparast, M. (2017). Neurobiology of axonal transport defects in motor neuron diseases: Opportunities for translational research? Neurobiol Dis 105, 283-299. 
Eathiraj, S., Pan, X., Ritacco, C., and Lambright, D.G. (2005). Structural basis of family-wide Rab GTPase recognition by rabenosyn-5. Nature 436, 415-419.

Emsley, P., Cowtan, K., IUCr (2004). Coot: model-building tools for molecular graphics. Acta Crystallogr. D Biol. Crystallogr. 60, 2126-2132.

Frank, J., Radermacher, M., Penczek, P., Zhu, J., Li, Y., Ladjadj, M., and Leith, A. (1996). SPIDER and WEB: processing and visualization of images in 3D electron microscopy and related fields. Journal of Structural Biology 116, 190-199.

Ghaemi, Z., Guzman, I., Gnutt, D., Luthey-Schulten, Z., and Gruebele, M. (2017). Role of Electrostatics in Protein-RNA Binding: The Global vs the Local Energy Landscape. Journal of Physical Chemistry B 121, 8437-8446.

Grosshans, B.L., Ortiz, D., and Novick, P. (2006). Rabs and their effectors: achieving specificity in membrane traffic. Proceedings of the National Academy of Sciences 103, 11821-11827.

Haas, A.K., Fuchs, E., Kopajtich, R., and Barr, F.A. (2005). A GTPase-activating protein controls Rab5 function in endocytic trafficking. Nat Cell Biol 7, 887-893.

Horiuchi, H., Lippé, R., McBride, H.M., Rubino, M., Woodman, P., Stenmark, H., Rybin, V., Wilm, M., Ashman, K., Mann, M., et al. (1997). A novel Rab5 GDP/GTP exchange factor complexed to Rabaptin-5 links nucleotide exchange to effector recruitment and function. Cell 90, 1149-1159.

Huis In 't Veld, P.J., Jeganathan, S., Petrovic, A., Singh, P., John, J., Krenn, V., Weissmann, F., Bange, T., and Musacchio, A. (2016). Molecular basis of outer kinetochore assembly on CENP-T. Elife 5, 576.

Jagoe, W.N., Lindsay, A.J., Read, R.J., McCoy, A.J., McCaffrey, M.W., and Khan, A.R. (2006). Crystal structure of rab11 in complex with rab11 family interacting protein 2. Structure 14, 1273-1283.

Kabsch, W. (2010). Xds. Acta Crystallogr. D Biol. Crystallogr. 66, 125-132.

Kim, Y.-G., Raunser, S., Munger, C., Wagner, J., Song, Y.-L., Cygler, M., Walz, T., Oh, B.-H., and Sacher, M. (2006). The architecture of the multisubunit TRAPP I complex suggests a model for vesicle tethering. Cell 127, 817-830.

Kramer, K., Sachsenberg, T., Beckmann, B.M., Qamar, S., Boon, K.L., Hentze, M.W., Kohlbacher, O., and Urlaub, H. (2014). Photo-cross-linking and high-resolution mass spectrometry for assignment of RNA-binding sites in RNA-binding proteins. Nature Methods 11, 1064-1070.

Lanzetti, L., Rybin, V., Malabarba, M.G., Christoforidis, S., Scita, G., Zerial, M., and Di Fiore, P.P. (2000). The Eps8 protein coordinates EGF receptor signalling through Rac and trafficking through Rab5. Nature 408, 374-377.

Lauer, J., Segeletz, S., Cezanne, A., Guaitoli, G., Raimondi, F., Gentzel, M., Alva, V., Habeck, M., Kalaidzidis, Y., Ueffing, M., et al. (2019). Auto-regulation of Rab5 GEF 
activity in Rabex 5 by allosteric structural changes, catalytic core dynamics and ubiquitin binding. Elife 8 .

Lee, S.J., Kim, S.J., Kim, I.K., Ko, J., Jeong, C.S., Kim, G.H., Park, C., Kang, S.O., Suh, P.G., Lee, H.S., et al. (2003). Crystal structures of human DJ-1 and Escherichia coli Hsp31, which share an evolutionarily conserved domain. J. Biol. Chem. 278, 44552-44559.

Liao, Y.-C., Fernandopulle, M.S., Wang, G., Choi, H., Hao, L., Drerup, C.M., Patel, R., Qamar, S., Nixon-Abell, J., Shen, Y., et al. (2019). RNA Granules Hitchhike on Lysosomes for Long-Distance Transport, Using Annexin A11 as a Molecular Tether. Cell 179, 147-164.e20.

Liebschner, D., Afonine, P.V., Baker, M.L., Bunkóczi, G., Chen, V.B., Croll, T.I., Hintze, B., Hung, L.W., Jain, S., McCoy, A.J., et al. (2019). Macromolecular structure determination using $X$-rays, neutrons and electrons: recent developments in Phenix. Acta Crystallogr Sect D Struct Biol 75, 861-877.

Lunde, B.M., Moore, C., and Varani, G. (2007). RNA-binding proteins: modular design for efficient function. Nat Rev Mol Cell Biol 8, 479-490.

Mayne, L., Kan, Z.-Y., Chetty, P.S., Ricciuti, A., Walters, B.T., and Englander, S.W. (2011). Many Overlapping Peptides for Protein Hydrogen Exchange Experiments by the Fragment Separation-Mass Spectrometry Method. J Am Soc Mass Spectrom 22, 1898-1905.

McCoy, A.J., Grosse-Kunstleve, R.W., Adams, P.D., Winn, M.D., Storoni, L.C., and Read, R.J. (2007). Phaser crystallographic software. J Appl Crystallogr 40, 658-674.

Medioni, C., Mowry, K., and Besse, F. (2012). Principles and roles of mRNA localization in animal development. Development 139, 3263-3276.

Miaczynska, M., Christoforidis, S., Giner, A., Shevchenko, A., Uttenweiler-Joseph, S., Habermann, B., Wilm, M., Parton, R.G., and Zerial, M. (2004). APPL proteins link Rab5 to nuclear signal transduction via an endosomal compartment. Cell 116, 445456.

Mishra, A., Eathiraj, S., Corvera, S., and Lambright, D.G. (2010). Structural basis for Rab GTPase recognition and endosome tethering by the $\mathrm{C}_{2} \mathrm{H}_{2}$ zinc finger of Early Endosomal Autoantigen 1 (EEA1). Proc. Natl. Acad. Sci. U.S.a. 107, 10866-10871.

Mofatteh, M. (2020). mRNA localization and local translation in neurons. AIMS Neurosci 7, 299-310.

Moriya, T., Saur, M., Stabrin, M., Merino, F., Voicu, H., Huang, Z., Penczek, P.A., Raunser, S., and Gatsogiannis, C. (2017). High-resolution Single Particle Analysis from Electron Cryo-microscopy Images Using SPHIRE. Journal of Visualized Experiments : JoVE.

Murray, D.H., Jahnel, M., Lauer, J., Avellaneda, M.J., Brouilly, N., Cezanne, A., Morales-Navarrete, H., Perini, E.D., Ferguson, C., Lupas, A.N., et al. (2016). An 
endosomal tether undergoes an entropic collapse to bring vesicles together. Nature $537,107-111$.

Müller, M.P., and Goody, R.S. (2018). Molecular control of Rab activity by GEFs, GAPs and GDI. Small GTPases 9, 5-21.

Nielsen, E., Christoforidis, S., Uttenweiler-Joseph, S., Miaczynska, M., Dewitte, F., Wilm, M., Hoflack, B., and Zerial, M. (2000). Rabenosyn-5, a novel Rab5 effector, is complexed with hVPS45 and recruited to endosomes through a FYVE finger domain. The Journal of Cell Biology 151, 601-612.

Nielsen, E., Severin, F., Backer, J.M., Hyman, A.A., and Zerial, M. (1999). Rab5 regulates motility of early endosomes on microtubules. Nat Cell Biol 1, 376-382.

Pascal, B.D., Willis, S., Lauer, J.L., Landgraf, R.R., West, G.M., Marciano, D., Novick, S., Goswami, D., Chalmers, M.J., and Griffin, P.R. (2012). HDX Workbench: Software for the Analysis of H/D Exchange MS Data. J Am Soc Mass Spectrom 23, $1512-1521$.

Pettersen, E.F., Goddard, T.D., Huang, C.C., Couch, G.S., Greenblatt, D.M., Meng, E.C., and Ferrin, T.E. (2004). UCSF Chimera-A visualization system for exploratory research and analysis. Journal of Computational Chemistry 25, 1605-1612.

Pfeffer, S.R. (2017). Rab GTPases: Master regulators that establish the secretory and endocytic pathways. Mol Biol Cell 28, 712-715.

Philips, A.K., Pinelli, M., de Bie, C.I., Mustonen, A., Määttä, T., Arts, H.H., Wu, K., Roepman, R., Moilanen, J.S., Raza, S., et al. (2017). Identification of C12orf4 as a gene for autosomal recessive intellectual disability. Clinical Genetics 91, 100-105.

Ramlaul, K., Palmer, C.M., and Aylett, C.H.S. (2019). A Local Agreement Filtering Algorithm for Transmission EM Reconstructions. Journal of Structural Biology 205, 30-40.

Ramlaul, K., Palmer, C.M., Nakane, T., and Aylett, C.H.S. (2020). Mitigating local over-fitting during single particle reconstruction with SIDESPLITTER. Journal of Structural Biology 211, 107545.

Rehman, A.U., Najafi, M., Kambouris, M., Gazali, Al, L., Makrythanasis, P., Rad, A., Maroofian, R., Rajab, A., Stark, Z., Hunter, J.V., et al. (2019). Biallelic loss of function variants in PPP1R21 cause a neurodevelopmental syndrome with impaired endocytic function. Human Mutation 40, 267-280.

Rohou, A., and Grigorieff, N. (2015). CTFFIND4: Fast and accurate defocus estimation from electron micrographs. Journal of Structural Biology 192, 216-221.

Sacher, M., Barrowman, J., Wang, W., Horecka, J., Zhang, Y.Y., Pypaert, M., and Ferro-Novick, S. (2001). TRAPP I implicated in the specificity of tethering in ER-toGolgi transport. Molecular Cell 7, 433-442. 
Scheres, S.H.W. (2012). RELION: implementation of a Bayesian approach to cryoEM structure determination. Journal of Structural Biology 180, 519-530.

Schnatwinkel, C., Christoforidis, S., Lindsay, M.R., Uttenweiler-Joseph, S., Wilm, M., Parton, R.G., and Zerial, M. (2004). The Rab5 effector Rabankyrin-5 regulates and coordinates different endocytic mechanisms. PLoS Biol 2, E261.

Schuhmacher, J.S., tom Dieck, S., Christoforidis, S., Landerer, C., Hersemann, L., Seifert, S., Giner, A., Toth-Petroczy, A., Kalaidzidis, Y., Schuman, E.M., et al. (2021). The novel Rab5 effector FERRY links early endosomes with the translation machinery. bioRxiv 2021.06.20.449167.

Shaikh, T.R., Gao, H., Baxter, W.T., Asturias, F.J., Boisset, N., Leith, A., and Frank, J. (2008). SPIDER image processing for single-particle reconstruction of biological macromolecules from electron micrographs. Nat Protoc 3, 1941-1974.

Shi, Z., Gao, H., Bai, X.-C., and Yu, H. (2020). Cryo-EM structure of the human cohesin-NIPBL-DNA complex. Science 368, 1454-1459.

Simonsen, A., Lippé, R., Christoforidis, S., Gaullier, J.M., Brech, A., Callaghan, J., Toh, B.H., Murphy, C., Zerial, M., and Stenmark, H. (1998). EEA1 links PI(3)K function to Rab5 regulation of endosome fusion. Nature 394, 494-498.

Stabrin, M., Schoenfeld, F., Wagner, T., Pospich, S., Gatsogiannis, C., and Raunser, S. (2020). TranSPHIRE: automated and feedback-optimized on-the-fly processing for cryo-EM. Nature Communications 11, 5716-14.

Stenmark, H., Aasland, R., Toh, B.H., and D'Arrigo, A. (1996). Endosomal localization of the autoantigen EEA1 is mediated by a zinc-binding FYVE finger. J. Biol. Chem. 271, 24048-24054.

Stenmark, H., Vitale, G., Ullrich, O., and Zerial, M. (1995). Rabaptin-5 is a direct effector of the small GTPase Rab5 in endocytic membrane fusion. Cell 83, 423-432.

Suleiman, J., Hashem, Al, A.M., Tabarki, B., Thihli, Al, K., Bi, W., and Hattab, El, A.W. (2018). PPP1R21 homozygous null variants associated with developmental delay, muscle weakness, distinctive facial features, and brain abnormalities. Clinical Genetics 94, 351-355.

Szklarczyk, D., Franceschini, A., Wyder, S., Forslund, K., Heller, D., Huerta-Cepas, J., Simonovic, M., Roth, A., Santos, A., Tsafou, K.P., et al. (2015). STRING v10: protein-protein interaction networks, integrated over the tree of life. Nucleic Acids Res 43, D447-D452.

Tall, G.G., Barbieri, M.A., Stahl, P.D., and Horazdovsky, B.F. (2001). Ras-activated endocytosis is mediated by the Rab5 guanine nucleotide exchange activity of RIN1. Dev Cell 1, 73-82.

Tang, G., Peng, L., Baldwin, P.R., Mann, D.S., Jiang, W., Rees, I., and Ludtke, S.J. (2007). EMAN2: an extensible image processing suite for electron microscopy. Journal of Structural Biology 157, 38-46. 
van der Brug, M.P., Blackinton, J., Chandran, J., Hao, L.-Y., Lal, A., MazanMamczarz, K., Martindale, J., Xie, C., Ahmad, R., Thomas, K.J., et al. (2008). RNA binding activity of the recessive parkinsonism protein DJ-1 supports involvement in multiple cellular pathways. Proceedings of the National Academy of Sciences 105, 10244-10249.

Vazquez-Pianzola, P., and Suter, B. (2012). Conservation of the RNA transport machineries and their coupling to translation control across eukaryotes. Comparative and Functional Genomics 2012, 1-13.

Wagner, T., Merino, F., Stabrin, M., Moriya, T., Antoni, C., Apelbaum, A., Hagel, P., Sitsel, O., Raisch, T., Prumbaum, D., et al. (2019). SPHIRE-crYOLO is a fast and accurate fully automated particle picker for cryo-EM. Commun Biol 2, 218-13.

Walters, B.T., Ricciuti, A., Mayne, L., and Englander, S.W. (2012). Minimizing back exchange in the hydrogen exchange-mass spectrometry experiment. J Am Soc Mass Spectrom 23, 2132-2139.

Wandinger-Ness, A., and Zerial, M. (2014). Rab proteins and the compartmentalization of the endosomal system. Cold Spring Harbor Perspectives in Biology 6, a022616-a022616.

Winn, M.D., Ballard, C.C., Cowtan, K.D., Dodson, E.J., Emsley, P., Evans, P.R., Keegan, R.M., Krissinel, E.B., Leslie, A.G.W., McCoy, A., et al. (2011). Overview of the CCP4 suite and current developments. Acta Crystallogr Sect D Struct Biol 67, 235-242.

Woodman, P.G. (2000). Biogenesis of the sorting endosome: the role of Rab5. Traffic $1,695-701$.

Wu, H., Turner, C., Gardner, J., Temple, B., and Brennwald, P. (2010). The Exo70 subunit of the exocyst is an effector for both Cdc42 and Rho3 function in polarized exocytosis. Mol Biol Cell 21, 430-442.

Yang, J., Anishchenko, I., Park, H., Peng, Z., Ovchinnikov, S., and Baker, D. (2020). Improved protein structure prediction using predicted interresidue orientations.

Proceedings of the National Academy of Sciences 117, 1496-1503.

Yang, Z., Fang, J., Chittuluru, J., Asturias, F.J., and Penczek, P.A. (2012). Iterative stable alignment and clustering of $2 \mathrm{D}$ transmission electron microscope images. Structure (London, England : 1993) 20, 237-247.

Yuan, W., and Song, C. (2020). The Emerging Role of Rab5 in Membrane Receptor Trafficking and Signaling Pathways. Biochemistry Research International 2020, 1-10.

Zarnack, K., and Feldbrügge, M. (2010). Microtubule-dependent mRNA transport in fungi. Eukaryot Cell 9, 982-990.

Zerial, M., and McBride, H. (2001). Rab proteins as membrane organizers. Nat Rev Mol Cell Biol 2, 107-117. 
Zheng, S.Q., Palovcak, E., Armache, J.-P., Verba, K.A., Cheng, Y., and Agard, D.A. (2017). MotionCor2: anisotropic correction of beam-induced motion for improved cryo-electron microscopy. Nature Methods 14, 331-332.

Zhu, G., Zhai, P., Liu, J., Terzyan, S., Li, G., and Zhang, X.C. (2004). Structural basis of Rab5-Rabaptin5 interaction in endocytosis. Nature Structural \& Molecular Biology 11, 975-983. 